\title{
Chloroflexi persisting for millions of years in oxic and anoxic deep-sea clay
}

\author{
Aurèle Vuillemin $^{1 *}$, Zak Kerrigan ${ }^{2}$, Steven D’Hondt $^{2}$ and William D. Orsi ${ }^{1,3 *}$ \\ ${ }^{1}$ Department of Earth and Environmental Sciences, Paleontology \& Geobiology, Ludwig-Maximilians-Universität München, \\ Richard-Wagner-Strasse 10, 80333 Munich, Germany. \\ ${ }^{2}$ Graduate School of Oceanography, University of Rhode Island, 215 South Ferry Road, 02882 Narragansett, USA. \\ ${ }^{3}$ GeoBio-CenterLMU, Ludwig-Maximilians-Universität München, Richard-Wagner-Strasse 10, 80333 Munich, Germany.

\section{Corresponding authors*:} \\ Dr. Aurèle Vuillemin \\ Ludwig-Maximilians-Universität München, Department of Earth and Environmental Sciences, \\ Paleontology \& Geobiology, Richard-Wagner-Strasse 10, 80333 Munich, Germany. \\ E-Mail: a.vuillemin@1rz.uni-muenchen.de \\ Phone/Fax: +49 (0) 8921806659 / +49 (0) 8921806601 \\ Prof. Dr. William D. Orsi \\ Ludwig-Maximilians-Universität München, Department of Earth and Environmental Sciences, \\ Paleontology \& Geobiology, Richard-Wagner-Strasse 10, 80333 Munich, Germany. \\ E-Mail: w.orsi@1rz.uni-muenchen.de \\ Phone/Fax: +49 (0) 8921806598 / +49 (0) 8921806601
}

Running title: Chloroflexi in oxic and anoxic deep-sea clay

Keywords: deep-sea clay; Chloroflexi; Dehalococcoidia; SAR202 clade; dehalogenase; Dsr and apr genes; North Atlantic Ocean; (homo)acetogenesis; metagenomes; metatranscriptomes.

Significance statement: Chloroflexi are widespread in energy-limited subseafloor sediments, both in oxic subseafloor sediments that are energetically limited by the availability of electron donors (organic matter) and in anoxic sediments that are energetically limited by the availability of high energy terminal electron acceptors. How Chloroflexi respond to these different forms of energy limitation over long time scales is poorly understood. We present new data that demonstrates how key differences in metabolism are manifested in different communities of aerobic and anaerobic Chloroflexi subsisting over millions of years in oxic and anoxic deep-sea clay. These data provide new insights into how certain Chloroflexi respond to different types of long-term energy limitation. 


\section{$37 \quad$ Abstract}

Chloroflexi are widespread in energy-limited subseafloor sediments, but how Chloroflexi respond to subseafloor energy limitation under oxic and anoxic conditions is poorly understood. Here, we characterize the diversity, abundance, activity, and metabolic potential of Chloroflexi in oxic and anoxic abyssal clay from three deep-sea cores covering up to 15 million years of sediment deposition, where Chloroflexi are a major component of the community throughout the entire cored sequence at all sites. In oxic red clay at two different sites, Chloroflexi communities exhibit net death over both 10-15 million year cored sequences, and gene expression was below detection despite the availability of oxygen as a high energy electron acceptor, indicating a reduced level of activity. In contrast at the anoxic site, Chloroflexi abundance and gene expression increase below the seafloor and peak in 2 to 3 million year old sediment. The anaerobic subseafloor Chloroflexi exhibited a homoacetogenic metabolism and potential for energetically efficient intracellular $\mathrm{H}_{2}$ recycling that have been proposed to confer a fitness advantage in energy-limited subseafloor habitats. Our findings indicate that the expression of this energy efficient metabolism in Chloroflexi coincides with net growth over million year timescales in deep-sea anoxic clay.

\section{Introduction}

Vast regions of the dark ocean have extremely slow sedimentation rates, ranging from 1 to 5 meters of sediment deposition per million years in abyssal regions (D'Hondt et al., 2015) and most organic flux to the sediment is consumed before it can be buried (Røy et al., 2012). As a result, microbial communities in abyssal subseafloor sediment are characterized by extremely low cell densities (Kallmeyer et al., 2012), experience extreme energy limitation over the long term (Hoehler and Jørgensen, 2013), even over million year timescales under both oxic and anoxic conditions (D'Hondt et al., 2015). The sedimentary material of the deep-sea is characterized by ultra-small $(<0.2 \mu \mathrm{m})$ clay particles that are 
highly pressurized under the $>5,000 \mathrm{~m}$ of overlying seawater, which likely hinders the motility of cells in this extreme environment, resulting in a complete separation from the surface after deposition.

Cells subsisting in deep-sea clays experience one of two types of energy limitation, limitation by electron donors or limitation by electron acceptors. In anoxic deep-sea clay, high energy electron acceptors of oxygen and nitrate are consumed at the sediment surface, and a main terminal electron acceptor is sulfate (Parks et al., 2005; Jørgensen et al., 2019). In contrast, the cells subsisting in subseafloor oxic deep-sea clay are constantly exposed to high energy electron acceptors of oxygen and nitrate throughout the entire sediment column (Røy et al., 2012), but are rather limited by the availability of electron donors in the form of organic matter (D'Hondt et al., 2015). This happens because the sedimentation rates are so slow in the oligotrophic ocean, that what little organic matter makes it to the seafloor is exposed to oxic conditions for exceptionally long timescales before it is buried, making the total concentration of subseafloor organic matter in oxic deep-sea red clay extremely low (Bradley et al., 2019). The end result is an oxic microbial subseafloor community that is limited by electron donors, compared to anoxic communities that have more organic matter but are energetically limited by electron acceptors (Orsi, 2018). The composition of these communities is shaped by selective survival of taxa pre-adapted to these conditions (Starnawski et al., 2017; Kirkpatrick et al., 2019) and includes many poorly characterized clades of Chloroflexi (Inagaki et al., 2006; Nunoura et al., 2018). However, the structure of these communities, their relationship to redox stratification, and their modes of selection as main constituents of the deep biosphere remain poorly constrained from the watersediment interface down through the deep subseafloor sediment column (Durbin and Teske, 2011; Walsh et al., 2016; Petro et al., 2019).

Chloroflexi are environmentally widespread. Their biogeography and modes of adaptation have been examined in various settings (Biddle et al., 2012) with variable salinities (Mehrshad et al., 2018), including shallow marine (Wilms et al., 2006; Petro et al., 2019), deep lacustrine (Vuillemin et al., 2018a; Kadnikov et al., 2019) and aquifer sediments (Hug et al., 2013) where they have been found to 
be abundant and highly diverse. They have also been reported as a predominant phylum in sewers (Krumins et al., 2018), anaerobic wastewater treatment systems (Shu et al., 2015), methanogenic reactors (Bovio et al., 2018), marine sponge microbiomes (Bayer et al., 2018) and deep subseafloor sediments (Orsi, 2018). Considering the scale of the marine subsurface (Kallmeyer et al., 2012), subseafloor Chloroflexi may be one of the most abundant microbial components on Earth and may drive key biogeochemical cycles on a global scale (Zinger et al., 2011; Hug et al., 2013; Fincker et al., 2020). However, many groups of subsurface microorganisms, including the Chloroflexi, remain uncultivated (Biddle et al., 2012; Solden et al., 2016). Thus, their metabolic properties remain poorly characterized, and the reasons for their broad ecological distribution and diversity have been elusive (Kaster et al., 2014; Wasmund et al., 2014; Sewell et al., 2017).

Within representative isolates among classes of Anaerolineae and Dehalococcoidia, diverse metabolic strategies include anoxic phototrophy (Klatt et al., 2013), fermentation (Yamada et al., 2006, 2017), and reductive dehalogenation (Duhamel and Edwards, 2006; Matturo et al., 2017). In terms of carbon cycling in marine sediments, the transformation of halogenated compounds has been studied extensively (Kittelmann and Friedrich, 2008; Kaster et al., 2014; Atashgashi et al., 2018; Kawai et al., 2014), whereas metagenome-assembled genomes (MAGs) and single-cell amplified genomes (SAGs) provide parallel evidence for respiration of sugars, fermentation, $\mathrm{CO}_{2}$ fixation via the Wood-Ljungdahl (W-L) pathway and acetogenesis with substrate-level phosphorylation (Hug et al., 2013; Sewell et al., 2017). The presence of genes encoding dissimilatory sulfite reductase $(D s r)$ and reversible adenylylsulfate reductase (apr) imply roles in sulfur cycling and respiration (Wasmund et al., 2017; Mehrshad et al., 2018; Vuillemin et al., 2018b). In addition, the phylum Chloroflexi exhibits a variety of complex monodermic cell envelope structures (Sutcliffe, 2011) and carries genes for multiple environmental adaptations across clades. These adaptations include protection against oxygen and osmotic stress (Wasmund et al., 2014) and aerobic oxidation of $\mathrm{H}_{2}, \mathrm{CO}$ and sulfur compounds at sub-atmospheric concentrations (Islam et al., 2019). Altogether, these metagenomic data suggest versatile respiratory 
modes with intricate heterotrophic and lithoautotrophic metabolisms, which may support long-term survival in dormant states and dispersal in deep marine environments (Jørgensen and Marshall, 2016;

Fullerton and Moyer, 2016).

In previous studies of slowly accumulating oxic and anoxic subseafloor clay from the abyssal North Atlantic covering up to 15 million years of depositional history (Vuillemin et al., 2018c and 2019), we found that Chloroflexi were a major component of the community in both settings. This abundance across multiple coring locations with varying redox states (oxic vs. anoxic) prompted a focused investigation of how the associated differences in long-term energy limitation (i.e. electron donors at oxic sites vs. electron acceptors at anoxic sites) select for metabolic features in Chloroflexi. In this study, we analyze 16S rRNA gene sequence, quantitative PCR (qPCR), metagenomic and metatranscriptomic data that identify metabolic features of the Chloroflexi associated with their selection and subsistence over million-year timescales in oxic and anoxic deep-sea clay at multiple deep-sea sampling locations. The data reveal differences in metabolism between aerobic and anaerobic Chloroflexi persisting under oxic and anoxic energy-limited conditions for millions of years below the abyssal seafloor.

\section{Results}

\section{Sedimentation rate and pore water geochemistry}

We analyzed long (ca. $30 \mathrm{~m}$ ) sediment cores from three deep-sea coring locations sites from R/V Knorr expedition KN223 in the Western North Atlantic, which were comprised of abyssal clay (Fig. 1A).

Dissolved oxygen is present throughout the clay at sites 11 and 12, with concentrations at the watersediment interface just below that of the overlying water (approximately $300 \mu \mathrm{M}$ ) and gradually decreasing with sediment depth (Fig. S1). Drawdown of $\mathrm{O}_{2}$ with sediment depth at these sites reflects oxidation of organic matter by aerobic microorganisms (Vuillemin et al., 2019). In contrast, dissolved 
oxygen at site 15 is restricted to the top mm of sediment. Sedimentation rate at both oxic sites sampled is estimated to be $1 \mathrm{~m}$ per million years (D’Hondt et al., 2015). Thus, the clay sampled at the deepest portion of the cores analyzed from both oxic sites (site 11, site 12) is about 30 million years old (Vuillemin et al., 2019). In contrast, anoxic site 15 is characterized by a mean sedimentation rate of about $3 \mathrm{~m}$ per million years (Fig. 1A). Given this rate, the deepest sediment sampled from the anoxic site 15 at 29 meters below seafloor (mbsf) is between 8 and 9 million years old.

\section{Diversity, density and taxonomy of 16S rRNA genes}

Four biological replicates of 16S rRNA genes (e.g. from separate DNA extractions) were sequenced at each sediment horizon from the anoxic sediment at site 15, which was compared to 16S rRNA genes from the two separate coring locations (site 11 and 12) that contain oxic clay. Based on 3711 OTUs obtained across all samples, non-metric multidimensional scaling (NMDS) analysis groups samples from the oxic sites separately from those of the anoxic site (Fig. S2) showing that oxygen conditions in the sediment had a statistically significant effect on community structure (ANOSIM: P 0.001, R= 0.897). All three sites exhibit similar values of total OTU richness (approximately 1500 at each site), Chloroflexi being the richest phylum (Fig. S2). Taxonomic assignment of 16S rRNA gene amplicons resulted in 791 Chloroflexi OTUs. Of these 791 OTUs, 555 are assigned to the class Dehalococcoidia, 136 are assigned to Anaerolineae, and the remaining 100 OTUs are in 9 different classes (Figs. S3-S4). Based on NMDS analysis of these 791 OTUs, the distribution of Chloroflexi between oxic and anoxic sediment was found to be statistically significant (ANOSIM: P 0.001, $\mathrm{R}=0.897$ ) (Fig. 1B).

At both oxic sites, the 16S rRNA gene densities (in copies $\times \mathrm{g}^{-1}$ wet sediment) are highest in the shallow subsurface, respectively $10^{7}$ and $10^{6}$ copies $\times \mathrm{g}^{-1}$ wet sediment, and decrease by 3 orders of magnitude within the underlying $0.5 \mathrm{mbsf}$ (Fig. 1C). At oxic site 12, our limit of detection $\left(10^{2} \times 16 \mathrm{~S}\right.$ rRNA gene copies per DNA extraction) is reached at $\sim 8$ mbsf, whereas at oxic site 11 , the density of $16 \mathrm{~S}$ rRNA genes increases by two orders of magnitude at $\sim 6$ mbsf before reaching the detection limit at $15 \mathrm{mbsf}$. Similar to the procedure described by Lloyd et al. (2020), we normalized the fractional abundance of the 
160 Chloroflexi 16S rRNA abundance to quantitative values using the qPCR determined 16S rRNA gene

161

162

163

164

165

166

167

168

169

170

171

172

173

174

175

176

177

178

179

180

181

182

concentrations as described previously (Vuillemin et al., 2019). The 16S rRNA gene density of

Chloroflexi at both oxic sites sampled decreases constantly with depth, reaching the limit of detection at 15 mbsf at site 11 and at 10 mbsf at site 12 . In contrast, the relative abundance of $16 \mathrm{~S}$ rRNA genes assigned to Chloroflexi increases gradually at both oxic sites from $<10 \%$ at the surface to about $40 \%$ in the deepest samples (Fig. 1C). The corresponding taxonomic assemblage is mainly composed of candidate clade S085 and SAR202 among Dehalococcoidia and uncultured Anaerolineales (Fig. 1C).

As implied by the NMDS analysis (Fig. 1B), the community composition at the anoxic site was significantly different by comparison. In contrast to the declining abundance of subseafloor Chloroflexi at oxic sites 11 and 12, at the anoxic site 15 the 16S rRNA gene density of Chloroflexi increases from $10^{5}$ copies at the seafloor surface up to two orders of magnitude in the deeper subsurface samples down to 2 mbsf, spanning ca. 1 million years of depositional history (Fig. 1C). Below this depth, the $16 \mathrm{~S}$ rRNA gene density of Chloroflexi decreases by an order of magnitude and remains constant down to the deepest sampled interval at 29 mbsf. Throughout the anoxic sediment column, Chloroflexi account for about $20 \%$ of the complete taxonomic assemblage (Fig. 1C). Within the uppermost 0.3 mbsf at the anoxic site 15 , Chloroflexi communities are similar to those of the oxic sites, namely candidate clades S085 and SAR202 and diverse uncultured Anaerolineales. However, below this depth at the anoxic site 15, the assemblages shift to presumed anaerobic candidates (e.g. GIF9, MSBL5, Sh7765B-AG-111) and uncultivated clades related to Dehalococcoides (Figs. 1C, S4). We acknowledge that primers targeting the V4-V6 regions as well as the average number of 16S rRNA gene copies in genomes of Chloroflexi $(2.2 \pm 1.2$ copies) can potentially result in quantitative biases between the clades mentioned (Větrovský and Badrian, 2013).

\section{Metabolic potential in metagenomes}

As described in several previous studies (Orsi et al., 2018; Ortega-Arbulù et al., 2019; Vuillemin et al., 2019; Orsi et al., 2020a), we used a bioinformatics pipeline involving a large aggregated genome 
database of predicted proteins including subsurface MAGs and SAGs (see Materials and Methods) for annotating putative functions of open reading frames (ORFs) in metagenomes and metatranscriptomes from particular "higher-level" (e.g. phyla or class level) taxonomic groups of microorganisms (e.g. Chloroflexi). This approach does not allow us to draw conclusions about specific populations within those groups (e.g. "MAGs" and "SAGs"), but does allow us to draw conclusions about metabolic traits derived specifically from higher-level taxonomic groups (Orsi et al., 2020a), such as Chloroflexi-related microorganisms given the ORF annotations provided. As is the case in all metagenomic studies, the incomplete nature of genomes in databases, together with the lower representation of sequenced genomes from candidate clades compared to cultured ones, make it likely that our pipeline misses annotation of ORFs that are derived from as-of-yet unsequenced Chloroflexi genomes that are not yet in databases. We acknowledge that some genes in databases annotated as being present in Chloroflexi MAGs might not actually derive from Chloroflexi chromosomes, but have been assigned to bins according to criteria that differ from study to study.

To assess the diversity of Chloroflexi recovered in metagenomes from the oxic and anoxic sites, we performed a phylogenetic analysis of the RNA polymerase sigma factor (RpoD) gene (Fig. 2A). We chose this gene for three reasons: (1) It is a universal single copy gene (Kawai et al., 2014); (2) the $R p o D$ gene has a faster evolutionary rate compared to $16 \mathrm{~S}$ rRNA genes and can be used to distinguish taxa at a relatively finer taxonomic level in phylogenetic analyses (Ghyselinck et al., 2013; Gupta et al., 2013); and (3) the RpoD gene was detected in Chloroflexi annotated contigs from metagenomes created at both oxic and anoxic sites, allowing for a comparative phylogenetic analysis of Chloroflexi in the metagenomes across sites. Phylogenetic analysis of the RpoD gene revealed the presence of several Chloroflexi clades among the SAR202 cluster in the oxic site metagenomes, and anaerobic clades of Dehalococcoidia in the anoxic site metagenomes (Fig. 2A), with affiliation to the recently published Chloroflexi genomes from deep-sea sediments (Fincker et al., 2020). Compared to the highly diverse candidate clades identified in the 16S rRNA gene taxonomy (Fig. S4), the phylogenetic analysis of 
RpoD gene indicated that the SAR202 clade and anaerobic deep-sea Dehalococcoidia were dominating the metagenomes at the oxic and anoxic sites, respectively. RpoD encoding genes from Chloroflexi were only detected in the metagenomes, no RpoD encoding transcripts from Chloroflexi were detected in the metatranscriptomes.

For both oxic sites, the number of unique ORFs in metagenomes assigned to Chloroflexi is highest in surface sediment and decreases by exponentially with increasing sediment depth (Fig. 3A). This mirrors the trend of declining Chloroflexi abundance with depth at the oxic sites based on qPCR and 16S rRNA gene sequencing (Fig. 1C). Because the multiple displacement amplification (MDA) step precludes a discussion of relative abundance of genes, we focus on presence or absence of unique ORFs assigned to Chloroflexi. In the shallow oxic sediment, Chloroflexi ORFs could be assigned to clusters of orthologous genes (COGs) involved in energy conversion, transport and metabolism of amino acids, carbohydrates, and coenzymes (Fig. 3A). As the detection of annotated protein-encoding ORFs decreases with depth, COG categories only include nucleotide, coenzyme and lipid transports and metabolisms. The relative detection of metabolic pathways and functional gene categories assigned to Chloroflexi indicate mainly aerobic respiration via cytochrome $\mathrm{C}$ oxidase and restricted potential for the tricarboxylic acid (TCA) cycle. Energy production relates to ATP synthase, NADH-quinone and -flavin reductase. Dehalogenases, peptidases, lipases, glycosidases, and oxidation of volatile fatty acids (VFAs) were all detected.

At the anoxic site, detection of annotated protein-encoding ORFs assigned to Chloroflexi in metagenomes remains constants with depth throughout the entire $29 \mathrm{~m}$ core sediment sequence (Fig. 3A). The main corresponding COG categories are energy production, transport and metabolism of amino acids, carbohydrates, coenzymes and lipids, but also include cell biogenesis, transcription and replication. The metabolic pathways from which the ORFs assigned to Chloroflexi are involved are related to sugar metabolism, the TCA cycle and W-L pathway. ORFs annotated as energy metabolism (electron carrier) genes from the Chloroflexi were identified at the anoxic site, including pyruvate and 
aldehyde ferredoxin oxidoreductase, NADH-quinone and -flavin oxidoreductase.

Also related to energy production, six Chloroflexi ORFs annotated as the alpha and beta subunits of the apr and Dsr genes were detected between 2 and $5 \mathrm{mbsf}$ in the metagenomes at the anoxic site 15 (Figs. 2B-2E), which are affiliated to Chloroflexi known from published SAG (Wasmund et al., 2014). No apr $A B$ or $\operatorname{Ds} A B$ encoding transcripts from Chloroflexi were detected in the metatranscriptomes.

Instead, numerous $a p r A B$ or $\operatorname{Ds} A B$ encoding transcripts were detected at anoxic site 15 , mostly from known groups of sulfate-reducing Deltaproteobacteria (Müller et al., 2015). At the oxic site 11, at a depth of $0.1 \mathrm{mbsf}$, aprA and $\operatorname{apr} B$ subunits were found to be encoded in metagenomes with affiliation to Chloroflexi ORFs (Figs. 2D-2E), but again no transcripts were detected with expression of these genes. Thus, the metabolic potential for the associated sulfur cycling in Chloroflexi is present at all sites, but its transcription was below detection in all cases. This confirmed metabolic potential for dissimilatory sulfate reduction among clades of Dehalococcoidia, whereas the absence of the related ORFs in our metatranscriptomes suggested that these genes are not actively transcripted by Chloroflexi in the anoxic sediment.

\section{Metabolic potential in metatranscriptomes}

At the anoxic site, the number of unique annotated protein-encoding ORFs assigned to Chloroflexi increases by two orders of magnitude from the seafloor surface to 5 mbsf. Below this depth, the number of unique ORFs assigned to Chloroflexi steadily decreases with depth until 15.9 mbsf. Below this depth, the only ORFs annotated were those assigned to groups of known contaminants from molecular kits including those from human skin and soil (Salter et al., 2014). Many of these same groups are common laboratory contaminants found in dust samples from our lab in 16S rRNA gene surveys (Pichler et al., 2018), and include Pseudomonas, Rhizobium, Acinetobacter, and Staphylococcus. We interpreted the sudden dominance of ORFs with similarity these common contaminants below 15.9 mbsf to be indicative of our limit of RNA detection, whereby a lower amount of extracted RNA from the in situ active community becomes overprinted by background "noise" from contaminating DNA. 
In metatranscriptomes from $0.1 \mathrm{mbsf}$ at the anoxic site $15, \mathrm{COG}$ annotations of ORFs assigned to

Chloroflexi only included biogenesis, DNA replication, protein turnover, and motility (Fig. 3B).

Interestingly below $0.1 \mathrm{mbsf}$, there was no longer any gene expression of ORFs encoding proteins involved in motility. This indicates that motility of Chloroflexi was possibly restricted to the upper sediment layers, with starvation-induced loss of this function below (Wei and Bauer, 1998; Zhu and Gao, 2020). Several COG categories increased in relative abundance in the metatranscriptomes of Chloroflexi at deeper depths, which included ORFs involved in cellular defense, prophages, motility and secondary metabolites (Fig. 3B). These COG categories were expressed in the metatranscriptomes but were not detected in the metagenomes, indicating a relatively high level of expression. Rather, the increasing relative abundance of these COG categories in the metatranscriptomes may correspond to activities that increase in relative abundance over time since burial. While a bias by MDA amplified metagenomes cannot be completely ruled out, it is unlikely that MDA would be biased against entire COG categories. This is consistent with a higher number of unique annotated ORFs assigned to Chloroflexi deeper in the subsurface, which is an indication of their increased activity in the older sediments (Fig. 3B). In the metatranscriptomes, Chloroflexi ORFs encoding proteins involved in metabolic pathways could be assigned to sugar metabolism, and the W-L pathway. The deepest ORFs assigned to Chloroflexi at 15.9 mbsf are involved in cellular maintenance activities, such as DNA repair and protein turnover. Expression of Chloroflexi ORFs involved in energy production annotated as aldehyde and pyruvate ferredoxin oxidoreductase, NADH-quinone oxidoreductase (Nuo), ATP synthase and NADH-flavin oxidoreductase were also detected (Fig. 3B).

An NMDS analysis based on all annotated protein-encoding ORFs obtained from metagenomes and metatranscriptomes (ANOSIM: P 0.001, $\mathrm{R}=0.56$ ), as well as those exclusively assigned to Chloroflexi (ANOSIM: P $0.005, \mathrm{R}=0.34$ ), clearly separates all of the metagenome and metatranscriptome samples from both oxic sites from those recovered from the anoxic site (Fig. 4). This demonstrates that the metabolic potential is significantly different, not only within the entire microbial community, but 
between aerobic and anaerobic Chloroflexi as well. Because the sediment samples are millions of years old, selection for specific metabolisms has occurred in these different Chloroflexi over exceptionally long timescales.

From the oxic site samples, no metatranscriptomes of sufficient quality could be obtained. We attempted to extract RNA and make metatranscriptome libraries from the samples, but in every sample the only recovered ORFs annotated were those assigned to groups of known contaminants from molecular kits (Salter et al., 2014) and dust samples from our lab (Pichler et al., 2018). We interpreted the dominance of ORFs with similarity to these common contaminants to be a clear indication of contamination, since the metagenomes and 16S rRNA gene datasets showed a completely different community structure that was dominated by the Chloroflexi. In none of the metatranscriptomes from the oxic site could we retrieve any ORFs annotated to Chloroflexi genomes, indicating that the gene expression and overall activity of Chloroflexi at the oxic sites were very low.

Phylogenetic affiliation of ORFs from the metatranscriptomes encoding the DsrAB genes (Fig. 2B-C) pointed to Deltaproteobacteria as the main active sulfate-reducing bacteria subsisting in the anoxic subseafloor clay at site 15, whereas a smaller number of expressed ORFs were affiliated with Gammaproteobacteria reverse $D s r A B$ ( $r D s r$ ) involved in sulfide oxidation (Loy et al., 2009).

Phylogenetic analysis of the ORFs encoding aprA and $\operatorname{aprB}$ proteins identified in our metagenomes and metatranscriptomes pointed to Delta- and Gammaproteobacteria as the main clades actively expressing these genes in the anoxic subseafloor at site 15 (Figs. 2C-2D). Five ORFs assigned to aprAB genes in metagenomes from oxic site 11 and anoxic site 15 were affiliated to Chloroflexi MAGs among the SAR202 cluster (Mehrshad et al., 2018), revealing metabolic potential for aprA and aprB gene in both oxic and anoxic subseafloor sediment. However, same as for the DsrAB genes encoded by the subseafloor Chloroflexi, there was no detection for active transcription of these genes by Chloroflexi in our metatranscriptomes. 


\section{Discussion}

311 We present new data from million year old sediments that provide new insights into how life survives under energy-limited conditions sediments, both in oxic and anoxic sediments, over million-year

timescales. Subseafloor life in oxic sediments is energetically limited by the availability of electron donors (organic matter), whereas in anoxic sediments it is energetically limited by the availability of high energy terminal electron acceptors. Since Chloroflexi constitute a substantial part of the subseafloor communities under both settings, we investigated metabolic potentials and strategies that may allow them to actively survive under extreme energy limitation and persist in subseafloor sediment for millions of years after burial.

Chloroflexi in oxic deep-sea clay. At both oxic sites, the Chloroflexi were dominated by the SAR202

Phylogenetic analysis of the Chloroflexi RpoD gene proteins from confirmed taxonomic affiliation of 
335

336

337

338

transcriptional activity that actually increase with depth (Figs. 3A-3B). According to Mehrshad et al.

(2018), some SAR202 Chloroflexi may use the apr gene during aerobic sulfate metabolism, possibly in the oxidation of sulfite or thiosulfate produced during the breakdown of organic sulfur molecules. The SAR202 in the oxic clays also contain this apr gene (Fig. 2D), which is related to apr genes from some Euryarchaeota (Mehrshad et al. 2018), but no metatranscriptomes from the oxic clays could be produced presumably due to the ultra-low metabolic activities of the cells. Thus, it remains unknown whether the subseafloor SAR202 Chloroflexi expressed this apr gene or not, and whether they are engaged in sulfite or thiosulfate oxidation. Nevertheless, the presence of this gene in the metagenomes indicates the metabolic potential for such processes.

Chloroflexi in anoxic deep-sea clay. The increase in gene density below the seafloor (Fig. 1C) and number of unique expressed ORFs (Fig. 3) suggest that Chloroflexi proliferate in the deep anoxic clay and experience net growth over the top few meters of sediment. The Chloroflexi 16S rRNA genes at the seafloor surface at anoxic site 15 were predominantly affiliated with uncultivated Anaerolineales and the Dehalococcoidia. Their most closely related cultivates (Fig. S4), i.e. Anaerolinea, Leptolinea (Yamada et al., 2006), Longilinea (Yamada et al., 2017), Pelolinea (Imachi et al., 2014), and Flexilinea (Sun et al., 2016), are known to mainly ferment sugars but, unlike their main class representative Dehalococcoides mccartyi (Löffler et al., 2013), they do not grow on VFAs or alcohols as electron donors or haloorganic electron acceptors. The taxonomic composition of the Chloroflexi assemblage transitioned away from the SAR202 at the surface of site 15 towards anaerobic clades of Dehalococcoides with increasing depth (Fig. 1C). Phylogenetic analysis of the Chloroflexi RpoD encoded proteins confirmed the presence of Dehaloccoidia clades in the metagenomes from the anoxic site (Fig. 2A). These metagenomes further revealed the presence of Chloroflexi assigned ORFs annotated to proteins involved in sugar metabolism, the W-L pathway, pyruvate ferredoxin oxidoreductase, ATP synthase, and NADH-quinone oxidoreductase (Fig. 3A). The NMDS plots for 16S rRNA genes (Fig. 1B) and metagenomes (Fig. 4) significantly separate oxic and anoxic samples, 
indicating that the presence or absence of $\mathrm{O}_{2}$ exerts very strong selection pressure (ANOSIM: P 0.001,

$\mathrm{R}=0.897 ; \mathrm{P} 0.001, \mathrm{R}=0.56)$.

362

The observation that metatranscriptomes at the anoxic site recovered relatively high numbers of ORFs annotated to Chloroflexi, whereas no ORFs from metatranscriptomes could be annotated to Chloroflexi from the oxic site samples, indicates that anaerobic Chloroflexi in the anoxic subseafloor clay had a generally higher level of activity compared to aerobic Chloroflexi in the oxic subseafloor clays (Figs. 2A-2B). At the anoxic site at a depth of 0.1 mbsf, Chloroflexi ORFs in metatranscriptomes were involved in translation, replication and protein turnover (Fig. 3B). As the density of 16S rRNA genes (Fig. 1C) and number of annotated protein-encoding ORFs (Fig. 2B) increases with sediment depth, the number of different COG categories in the metatranscriptomes assigned to Chloroflexi increases, suggesting that the metabolic activity of the anaerobic Chloroflexi increases with sediment depth at the anoxic site. These additional COG categories from the metatranscriptomes included transcription, energy production, cellular defense, prophages, and production of secondary metabolites. In the deepest metatranscriptome at 15.9 mbsf, the only annotated protein-encoding ORFs that were assigned to Chloroflexi were involved in DNA repair, nucleotide transport, metabolism and protein turnover, which are indicative of cellular maintenance processes in sediments that have an estimated age of 5 million years (Fig. 3B).

The metatranscriptomes from the anoxic site point to fermentation and acetogenesis as key metabolic mechanisms for anaerobic subseafloor Chloroflexi, which was already predicted from genome analysis of subseafloor Chloroflexi (Sewell et al., 2017; Fincker et al., 2020). The detection of ORFs assigned to Chloroflexi with similarity to the methyl-viologen Fe-S reducing and F420 non-reducing Ni-Fe hydrogenases $(M V H s)$ indicated the potential for production of molecular hydrogen (Vignais et al., 2001; Shafaat et al., 2013) (Fig. 5). The utilization of a partial W-L pathway in anaerobic carbon metabolism has been shown in the cultivated Chloroflexi strain Dehalococcoides mccartyi, which uses a partial W-L pathway for $\mathrm{C} 1$ compound assimilation from either $\mathrm{CO}_{2}$ reduction or acetate oxidation 
385 (Zhuang et al., 2014; Fincker et al., 2020). Expression of Chloroflexi ORFs annotated as pyruvate

ferredoxin oxidoreductase (Fig. 3B) may provide a link between the W-L pathway and other anabolic pathways (Wasmund et al., 2014). Here, the ORFs assigned to Chloroflexi with similarity to W-L pathway proteins that are actively expressed included formate dehydrogenase $(f d h)$, methylenetetrahydrofolate reductase $(M T H F R)$, carbon monoxide dehydrogenase $(C O D H)$ and acetylCoA synthase ( $c d h A)$ (Fig. 5). Many homoacetogenic bacteria use the Rnf complex to generate a chemiosmotic gradient of $\mathrm{Na}^{+}$ions in order to synthesize ATP at the membrane (Peters et al., 2016; Schuchmann and Müller, 2019). However, Dehalococcoidia appear to use the NADH-quinone oxidoreductase (Nuo) to create a proton gradient in order to generate a chemiosmotic potential for ATP synthesis (Wasmund et al., 2017). Nuo yields reduced energy compared to the flavin-dependent oxidoreductase (Buckel and Thauer, 2018). ORFs with similarity to Nuo and ATP synthases are expressed by the Chloroflexi in greater abundances down to $10 \mathrm{mbsf}$ (Fig. 3B), which potentially related to active ATP production via chemiosmotic proton pumping with Nuo. Ferredoxin and flavodoxin (Fig. 5) are expressed by the Chloroflexi at these same depths and are likely involved as electron carriers in cellular redox reactions (Peters et al., 2016; Buckel and Thauer, 2018).

Additional Chloroflexi ORFs with similarity to W-L pathway proteins were also present in the metagenomes, which were annotated as methylene-tetrahydrofolate dehydrogenase/cyclohydrolase $(D H C H)$, and acyl-CoA dehydrogenase $(A C A D)$ (Fig. 5). This indicates that some of the anaerobic Chloroflexi in the anoxic subseafloor clay have metabolic potential for $\beta$-oxidation of VFAs.

Chloroflexi ORFs annotated as acetate kinase, which is the enzyme that yields one ATP during substrate level phosphorylation (SLP) in (homo)acetogenic bacteria (Schuchmann and Müller, 2019), was detected in the metagenomes (Table S2) but not in the metatranscriptomes (Table S3). This might indicate ATP production via chemiosmotic ion gradients at the membrane as a preferential source of energy production (as opposed to dephosphorylation of acetyl-phosphate) by anaerobic Chloroflexi in these million year old anoxic clays. 
Survival mechanisms of Chloroflexi in oxic and anoxic subseafloor clay. The organic matter present at very low concentrations in abyssal clay is dominated by amide and carboxylic carbon and generally proteinaceous (Estes et al., 2019). We infer that Chloroflexi actively utilize this organic matter in the anoxic subseafloor clays, based on the relatively high expression levels of peptide transporters and peptidases (Fig. 3B). During fermentation of amino acids, hydrogen is produced (Buckel and Barker, 1974; Barker, 1981), which can ultimately be cycled inside the cell and channeled into the partial W-L pathway (Wiechmann et al., 2020). Amino acid substrates are possibly the most important of all fermentation substrates in the subseafloor because cells subsist in these environments on necromass (Bradley et al., 2019), and most of cellular material is protein by weight (Orsi et al., 2020b). Thus, the proteinaceous components of deep-sea clay (Estes et al., 2019) likely serve an important role in sustaining the activity of anaerobic Chloroflexi seen here, possibly via the fermentation of amino acids, for millions of years after they are buried below the seafloor.

Such intracellular $\mathrm{H}_{2}$ recycling by homoacetogenic Chloroflexi in the subseafloor has been shown recently in a genomic analysis (Fincker et al., 2020), whereby a higher energy efficiency of this metabolism confers a fitness advantage for subseafloor homoacetogens including Chloroflexi. If true, this may imply that such acetogens do not require an $\mathrm{H}_{2}$ producing syntrophic partner (Wiechmann et al., 2020). Rather, they make the $\mathrm{H}_{2}$ themselves via fermentation and then consume it via the W-L pathway, which likely helps to recycle NADH and ferredoxin pools, leading to a higher ATP yield via chemiosmotic pumping of ion gradients at the membrane (Schuchmann and Müller, 2019). The close affiliation of a clade containing many Chloroflexi assigned rpoD sequences from the metagenomes of anoxic site 15 with $R p o D$ sequences from deep-sea Chloroflexi MAGs (Fig. 2A) that have such a homoacetogenic metabolism (Fincker et al., 2020), further supports the conclusion that many of the transcriptionally active Chloroflexi at anoxic site 15 are surviving via homoacetogenesis.

The genomic potential for dissimilatory sulfate reduction in uncultivated clades of Chloroflexi from marine sediments has been identified previously (Wasmund et al., 2017; Mehrshad et al., 2018), which 
could be an important metabolic feature of Chloroflexi to survive under the energy-limited conditions for long time periods below the seafloor. The detection of ORFs assigned to aprAB and $D s r A B$ genes in the metagenomes from the anoxic site (Fig. 2B-2E), indicates that some of the Chloroflexi have potential for dissimilatory sulfate reduction in the anoxic subseafloor sediment. Dissimilatory sulfate reduction could be utilized by subseafloor Chloroflexi to promote increased protein synthesis and growth in the million year old sediments sampled here. However, expression of ORFs encoding the aprA and $\operatorname{Ds} A B$ proteins assigned to Chloroflexi were not detected in the metatranscriptomes from the same samples (Fig. 5), which suggests that dissimilatory sulfate reduction is not a major energy yielding activity under these conditions compared to the Deltaproteobacteria that, in contrast, expressed many ORFs of DsrAB and aprAB genes (Figs. 2B-2E). The most genes expressed by the anaerobic Chloroflexi at the anoxic site appear to be rather involved in a homoacetogenic lifestyle, which has been proposed to be $\mathrm{H}_{2}$-syntroph independent and involves intracellular re-oxidation of $\mathrm{H}_{2}$ for $\mathrm{CO}_{2}$ fixation via the W-L pathway (Finker et al., 2020). The gene expression data assigned to Chloroflexi from these million year old deep-sea clays indicate that this proposed metabolic mechanism is actively used by subseafloor anaerobic Chloroflexi, and is more expressed compared to Chloroflexi genes involved in dissimilatory sulfate reduction. Based on this, we speculate that the subseafloor Chloroflexi, that have a potential for dissimilatory sulfate reduction, avoid competing for sulfate with sulfate-reducing bacteria by applying a homoacetogenic lifestyle instead. Our data show that this is correlated with increased net growth over a ca. 1 million year interval in the upper $5 \mathrm{~m}$ of deep-sea clay sediment at anoxic site 15 .

Our metatranscriptomes show that Deltaproteobacteria are the main sulfate-reducing bacteria that are presently active in the anoxic subseafloor (Figs. 2B-2E). ORFs expressing the $r D s r A B$ and reversible aprA genes (Loy et al., 2009) further suggest that some Gammaproteobacteria are active in the samples (Fig. 2), but it remains unclear what $r D s r$ expressing organisms (e.g. $\mathrm{H}_{2} \mathrm{~S}$ oxidizing bacteria) would use as a terminal electron acceptor. However, since the $D s r$ and $r D s r$ enzymes are potentially reversible (Loy et al., 2009; Müller et al., 2015; Orsi et al., 2016), the expression of the $r D s r$ genes from the 
usually sulfide oxidizing Gammaproteobacteria may function in these sediments as Dsr genes and, in this case, the $D s r$ enzyme in organisms may actually be performing sulfate reduction instead of sulfide oxidation.

Metagenomes from the oxic sites 11 and 12 also have Chloroflexi assigned aprAB encoding genes, but those are derived from the SAR202 clade (Figs. 2D-2E). Similar to anoxic site 15, there was no detectable expression of apr $A B$ encoding transcripts at the oxic sites. Moreover, there were no Dsr $A B$ genes assigned to Chloroflexi that were detected in metagenomes or metatranscriptomes from any of the oxic site samples (Figs. 2B-2C). Sequences of the aprAB genes from oxic subseafloor Chloroflexi SAR202 clade constitute a separate group (Figs. 2D-2E), which have been proposed to correspond to a sulfur-oxidizing version of the aprA genes (e.g. reversed reaction) instead of sulfate reduction, that some SAR202 clade organisms could use to oxidize sulfite derived from organosulfur compounds (Mehrshad et al., 2018). In addition, aerobic Chloroflexi from the SAR202 clade at the oxic sites mainly display metabolic potential for aerobic sugar metabolism and a partial TCA cycle, and the entire oxidative and non-oxidative pentose phosphate pathway (Fig. 5), implying a potential mechanism to store and consume sugars over millions of years. Chloroflexi assigned ORFs from the oxic site metagenomes annotated as carbon monoxide dehydrogenase, heterodisulfide reductase, and Nuo (Fig. 5) have been suggested previously to be signatures of an aerobic carboxidotrophy lifestyle (Carr et al., 2019; Cordero et al., 2019; Islam et al., 2019). It is possible that the aerobic Chloroflexi SAR2020 clade organisms dominating in the subseafloor oxic clay at the two sampled locations are using a similar aerobic carboxidotrophy metabolism. Oxidation of $\mathrm{CO}$ has been shown to be energetically favorable in cultivated bacteria (Cordero et al., 2019; Islam et al., 2019), which might be advantageous for the aerobic Chloroflexi subsisting in oxic subseafloor clay in the absence of abundant organic matter (Bradley et al., 2019). 


\section{Conclusions}

485 Our findings demonstrate that transcriptionally active anaerobic, homoacetogenic Chloroflexi proliferate

486

487

488

489

490

491

492

493

494

495

496

497

498

499

500

501

502

503

504

505

506

507

508

in anoxic abyssal clay sediments that are 2 to 3 million- years old, and exhibit higher activity compared

to aerobic Chloroflexi from oxic abyssal clays. The gene expression data support prior predictions of potential (homo)acetogenic lifestyle, independent of an $\mathrm{H}_{2}$-producing syntrophic partner, for some subseafloor Chloroflexi. A metabolic potential for aerobic oxidation of CO in the aerobic Chloroflexi might be related to their successful dominance in the oxic abyssal clay communities. Because

Chloroflexi communities in the oxic subseafloor exhibit net death over the million year time scales (e.g. increasing depth below seafloor), we infer that the majority of clade SAR202 cells persist in this setting as dormant or non-growing metabolic states. In contrast, anaerobic Chloroflexi appear to maintain detectable levels of transcriptional activity in anoxic abyssal clay deposited up to three million years ago.

We propose that this difference in activity between oxic and anoxic sites is related to the nature of the energy limitation. The oxic abyssal clays are energetically limited by the availability of electron donors (organic matter), which is why there is ample availability of electron acceptors in the form of oxygen and nitrate, and also why oxic clays are red (because the iron is oxidized). In contrast, the anoxic abyssal clays have higher concentrations of electron donors in the form of organic matter and are energy-limited by electron acceptors - all of the higher energy oxygen and nitrate are consumed via respiration close to the sediment surface. Given the high energy nature of oxygen and nitrate as electron acceptors, one might expect aerobic Chloroflexi in oxic abyssal clays to have higher activities compared to anaerobic Chloroflexi in anoxic abyssal clays, but our findings show that this is not the case. Rather, it appears that the activity of homoacetogenic Chloroflexi in anoxic sediment is correlated with the availability of electron donors in the form of organic matter rather than the availability of higher energy electron acceptors like oxygen and nitrate. This hypothesis could be tested with additional sampling of deep-sea cores from other oxic and anoxic clays, for example in new deep drilling expeditions to the South 
509 Pacific and North Pacific Gyres.

\section{Materials and Methods}

\section{Sampling expedition}

513 All samples were taken during Expedition KN223 of the R/V Knorr in the North Atlantic, from 26

514 October to 3 December 2014. At site $11\left(22^{\circ} 47.0^{\prime} \mathrm{N}, 56^{\circ} 31.0^{\prime} \mathrm{W}\right.$, water depth $\left.\sim 5600 \mathrm{~m}\right)$, site 12 $515\left(29^{\circ} 40.6^{\prime} \mathrm{N}, 58^{\circ} 19.7^{\prime} \mathrm{W}\right.$, water depth $\left.\sim 5400 \mathrm{~m}\right)$, and site $15\left(33^{\circ} 29.0^{\prime} \mathrm{N}, 5^{\circ} 10.0^{\prime} \mathrm{W}\right.$, water depth 5515 516

$\mathrm{m})$, successively longer sediment cores were retrieved using a multicorer $(\sim 0.4 \mathrm{~m})$, gravity corer $(\sim 3 \mathrm{~m})$ and the Woods Hole Oceanographic Institution (WHOI) piston-coring device ( $29 \mathrm{~m})$. Additional 518 details of sampling are published elsewhere (D'Hondt et al., 2015 and 2019). Dissolved oxygen 519 concentrations in the core sections were measured with optical $\mathrm{O}_{2}$ sensors as described previously 520 (D'Hondt et al., 2015). Sediment subcores were retrieved on the ship aseptically using end-cut sterile 521 syringes and kept frozen at $-80^{\circ} \mathrm{C}$ without any RNA shield until extraction in spring 2018 in the home 522 laboratory.

\section{DNA extraction, quantitative PCR, 16S rRNA genes}

524 For site 11 and 12, total DNA was extracted from $10 \mathrm{~g}$ of sediment per sample as previously described 525 (Vuillemin et al., 2019), whereas for site 15 we used $0.7 \mathrm{~g}$ of sediment per sample and diluted the final 526 extracts 10 times in ultrapure PCR water (Roche). DNA templates were used in quantitative PCR 527 (qPCR) amplifications with updated 16S rRNA gene primer pair 515F (5'- GTG YCA GCM GCC GCG 528 GTA A -3') with 806R (5'- GGA CTA CNV GGG TWT CTA AT -3') to increase our coverage of 529 Archaea and marine clades and run as previously described (Pichler et al., 2018). All qPCR reactions 530 were set up in $20 \mu \mathrm{L}$ volumes with $4 \mu \mathrm{L}$ of DNA template and performed as previously described 531 (Coskun et al., 2019). Reaction efficiency values in all qPCR assays were between 90\% and 110\% with 
$532 R^{2}$ values $>0.95 \%$ for the standards. For $16 \mathrm{~S}$ rRNA gene library preparation, qPCR runs were performed 533 with barcoded primer pair 515F and 806R. All 16S rRNA gene amplicons were purified from 1.5\% 534 agarose gels, normalized to $1 \mathrm{nM}$ solutions and pooled. Library preparation was carried out according to the MiniSeq System Denature and Dilute Libraries Guide (Protocol A, Illumina b). We combined 500 $\mu \mathrm{L}$ of the denatured and diluted $16 \mathrm{~S}$ rRNA library $(1.8 \mathrm{pM})$ with $8 \mu \mathrm{L}$ of denatured and diluted Illumina generated PhiX control library (1.8 pM) to assess sequencing error rates. For each run, we used four custom sequencing primers Read 1, Index 1, Index 2 and Read 2, which were diluted and loaded into the correct position of the reagent cartridge. An additional Index 2 sequencing primer was designed to enable the dual-index barcoding method on the MiniSeq (Pichler et al., 2018). Pooled libraries were sequenced on the Illumina MiniSeq platform at the GeoBio-Center LMU.

Demultiplexing and base calling were both performed using bcl2fastq Conversion Software v. 2.18 2010 and 2012) for MiniSeq read trimming and assembly, OTU picking and clustering at 97\% sequence identity, which we previously tested with mock communities sequenced on the same platform (Pichler et al., 2018). The initial step was to assemble paired-end reads using the fastq_merge pairs command with default parameters allowing for a maximum of five mismatches in the overlapping region. Stringent quality filtering was carried out using the fastq_filter command. We discarded low quality reads by setting the maximum expected error threshold (E_max), which is the sum of the error probability provided by the Q score for each base, to 1. Reads were de-replicated and singletons discarded. OTU representative sequences were identified by BLASTn searches against the SILVA 16S rRNA SSU NR99 reference database release 132 (Quast et al., 2013). All operational taxonomic units (OTUs) assigned to Chloroflexi were aligned with SINA online v.1.2.11 (Pruesse et al., 2007) and inserted in a 


\section{Metagenomes and transcriptomes}

558 Whole genome amplifications were performed on DNA extracts at dilution 10 times through a multiple 559 displacement amplification (MDA) step of 6 to 7 hours using the REPLI-g Midi Kit (QIAGEN) and 560 following the manufacturer's instructions. MDA-amplified PCR products were then diluted to DNA 561 concentrations of $0.2 \mathrm{ng} \mu \mathrm{L}^{-1}$ and used in metagenomic library preparations with the Nextera XT DNA

Library Prep Kit (Illumina, San Diego), then quantified on an Agilent 2100 Bioanalyzer System

563 (Agilent Genomics, Santa Clara) and normalized with the Select-a-Size DNA Clean and Concentrator

564 MagBead Kit (Zymo Research, Irvine) as previously described (Vuillemin et al., 2019), diluted to $1 \mathrm{nM}$ 565 and pooled.

566 For site 15, total RNA extractions were obtained from $3.5 \mathrm{~g}$ of wet sediments using the FastRNA Pro 567 Soil-Direct Kit (MP Biomedicals, Irvine) following the manufacturer's instructions, with the addition of $5684 \mu \mathrm{L}$ glycogen $\left(0.1 \mathrm{~g} \times \mathrm{mL}^{-1}\right)$ to increase yield during precipitation of the RNA pellet, and final elution 569 in $40 \mu \mathrm{L}$ PCR-grade water (Roche). Extraction blanks were processed alongside to assess laboratory 570 contamination. RNA extracts were quantified using the QuBit RNA HS Assay Kit (Thermo Fisher 571 Scientific, Waltham). DNAse treatment, synthesis of complementary DNA and library construction 572 were processed on the same day from $10 \mu \mathrm{L}$ of RNA templates, without any prior MDA step, using the 573 Trio RNA-Seq kit protocol (NuGEN Technologies, Redwood City). All libraries were quantified as 574 described above, diluted to $1 \mathrm{nM}$ and pooled for further sequencing on the MiniSeq platform (Illumina). 575 For site 11 and 12, RNA yields were too low to achieve amplification and sequencing.

576 The MiniSeq reads were trimmed and paired-end reads assembled into contigs, and open reading frames 577 (ORFs) extracted and functionally annotated as previously published (Ortega-Arbulú et al., 2019; 578 Vuillemin et al., 2019; Orsi et al., 2020a). Paired-end reads were trimmed and assembled into contigs 579 using CLC Genomics Workbench 9.5.4 (https://www.qiagenbioinformatics.com/), using a word size of 58020 , bubble size of 50, and a minimum contig length of 300 nucleotides. Reads were then mapped to the 
581 contigs using the following parameters (mismatch penalty $=3$, insertion penalty $=3$, deletion penalty $=$

582

3 , minimum alignment length $=50 \%$ of read length, minimum percent identity $=95 \%$ ). Coverage values were obtained from the number of reads mapped to a contig divided by its length (i.e. average coverage). Only contigs with an average coverage $>5$ were selected for ORF searches, and downstream analysis (Ortega-Arbulú et al., 2019). This protocol does not assemble ribosomal RNA (rRNA), and thus results are only discussed in terms of messenger RNA (mRNA).

Taxonomic identifications were integrated with the functional annotations, performing BLASTp searches of ORFs against an updated SEED (www.theseed.org) and NCBI RefSeq databases containing all predicted proteins from recently described high-quality draft genomes and single cell genomes from the NCBI protein database. Our database also included all fungal genomes from the NCBI RefSeq database (Orsi et al., 2018; Ortega-Arbulú et al., 2019). The total number of predicted proteins in the updated database was 37.8 million. We used the DIAMOND protein aligner version 0.9.24 (Buchfink et al., 2015). Cut-off values for assigning hits to specific taxa were performed at a minimum bit score of 50 , minimum amino acid similarity of 60 , and an alignment length of 50 residues. All scripts and code used to produce the analysis have been posted on GitHub (github.com/williamorsi/MetaProt-database), and we provide a link to the MetaProt on the GitHub page, as well as instructions within the scripts regarding how to conduct the workflows that we used.

We chose to focus on the coverage of total annotated protein-encoding ORFs detected, as opposed to the number of reads mapping per kilobase per ORF (for example, RPKM), to reduce potential bias from small numbers of "housekeeping" genes with potentially higher expression levels (Orsi et al., 2019 and 2020a). In addition, COG categories were assigned by comparing the metatranscriptome and metagenome annotated protein-encoding ORFs against the COG database (Galperin et al., 2015). Statistical analyses of beta-diversity were performed using RStudio v. 3.3.3 with the Bioconductor package (Huber et al., 2015). For both site 11 and 12, the metagenomes were sequenced for samples from four different depths to an average depth of 15 million reads, and de novo assembly resulted in a 
total of 177,498 contigs across all samples sequenced (Table S1). For site 15, metagenomes were sequenced for samples from five different depths at an average depth of 8.4 million reads $( \pm 2.5$ millions), assembled into 70,157 contigs. The metatranscriptomes from each sample at site 15 were produced in biological replicates and sequenced at an average depth of 4.0 million reads ( \pm 1.5 million). De novo assembly resulted in a total of 91,199 contigs across all samples sequenced (Table S1). For all metagenomes and metatranscriptomes, the read coverage of annotated protein-encoding ORFs assigned to Chloroflexi was normalized to the coverage of all transcripts and results shown as $\%$ of read coverage.

Taxonomic assignment of protein-encoding genes to Chloroflexi among the SAR202 and Dehalococcoidia clades was further confirmed in our metagenomes by phylogenetic analysis of the RNA polymerase sigma factor $(R p o D)$ gene proteins annotated as Chloroflexi, using alignments of 619 amino acid residues. Phylogenetic analyses of the predicted alpha and beta subunits of the Dsr and apr gene proteins were performed for all the corresponding annotated taxa in our metagenomes and metatranscriptomes, using 466, 433, 754 and 157 aligned amino acid sites respectively (Orsi et al., 2016). For each of the five marker gene phylogenies (RpoD, DsrA, DsrB, aprA, aprB), ORFs annotated to those genes from our annotation pipeline were aligned against their top two BLASTp hits in the NCBI-nr and SEED databases using MUSCLE (Edgar et al., 2004). Conserved regions of the alignments were selected in SeaView version 4.7 (Gouy et al., 2010), using Gblocks with the following settings: allowing for smaller final blocks, gap positions within the final blocks, and less strict flanking positions. Phylogenetic analysis of the resulting amino acid alignments of the predicted proteins were conducted in SeaView version 4.7 (Gouy et al., 2010), using RAxML (Stamatakis et al., 2012; Stamatakis, 2014) with BLOSUM62 as the evolutionary model and 100 bootstrap replicates. All alignments have been uploaded and will be made publicly available through the LMU Open Data website. 
bioRxiv preprint doi: https://doi.org/10.1101/2020.05.26.116590; this version posted May 27, 2020. The copyright holder for this preprint (which

was not certified by peer review) is the author/funder, who has granted bioRxiv a license to display the preprint in perpetuity. It is made available under aCC-BY-NC-ND 4.0 International license.

631 from sites 11 and 12 have Short Read Archive (SRA) BioSample accession numbers SAMN10924458

632 and SAMN10924459, corresponding to run accession numbers SRX5372537 to SRX5372545.

633 Metagenomes and transcriptomes from site 15 have accession number SAMN13317858 to

634 SAMN13317870, corresponding to run accession numbers SRR10481880 to SRR1048192. The 16S

635 rRNA data are available in SRA BioSample accessions SAMN10929403 to SAMN10929517 and

636 SAMN13324854 to SAMN13324920.

637

638 Acknowledgements

639 This work was supported primarily by the Deutsche Forschungsgemeinschaft (DFG) project OR 417/1-1

640 granted to W.D.O. The expedition was funded by the US National Science Foundation through grant

641 NSF-OCE-1433150. Shipboard microbiology efforts were supported by the Center for Dark Energy

642 Biosphere Investigations (C-DEBI grant NSF-OCE-0939564). This is a contribution of the Deep Carbon

643 Observatory (DCO). It is C-DEBI publication XXX.

644

645 Conflict of Interest

646 The authors have no conflict of interest to declare.

647

648 References

649 Atashgahi, S., Häggblom, M.M., and Smidt, H. (2018) Organohalide respiration in pristine 650 environments: implications for the natural halogen cycle. Environ Microbiol 20: 934-948.

651 Barker, H.A. (1981) Amino acid degradation by anaerobic bacteria. Annu Rev Biochem 50: 23-40. 
652 Bayer, K., Jahn, M.T., Slaby, B.M., Moitinho-Silva, L., and Hentschel, U. (2018) Marine sponges as 653 Chloroflexi hot spots: Genomic insights and high-resolution visualization of an abundant and diverse symbiotic clade. mSystems 3: e00150-18.

655 656 657 658 659 660 661

Biddle, J.F., Sylvan, J.B., Brazeltin, W.J., Tully, B.J., Edwards, K.J., Moyer ,C.L., et al. (2012) Prospects for the study of evolution in the deep biosphere. Front Microbiol 2: e285.

Bovio, P., Cabezas, A., and Etchebehere, C. (2018) Preliminary analysis of Chloroflexi populations in full scale UASB methanogenic reactors. J Appl Microbiol 126: 667-683.

Bradley, J.A., Amend, J.P., and LaRowe, D.E. (2019) Survival of the fewest: Microbial dormancy and maintenance in marine sediments through deep time. Geobiology 17:43-59.

Buchfink, B., Xie, C., and Huson, D.H. (2015) Fast and sensitive protein alignment using DIAMOND. Nat Methods 12: 59-60.

Buckel, W., and Barker, H.A. (1974) Two pathways of glutamate fermentation by anaerobic bacteria. J Bacteriol 117: 1248-1260.

Buckel, W., and Thauer, R.K. (2018) Flavin-based electron bifurcation, a new mechanism of biological energy coupling. Chem Rev 118: 3862-3886.

Carr, S.A., Jungbluth, S.P., Eloe-Fadrosh, E.A., Stepanauskas, R., Woyke, T., Rappé, M.S., et al. (2019) Carboxydotrophy potential of uncultivated hydrothermarchaeota form the subseafloor crustal biosphere. ISME J 13: 1457-1468.

Caporaso, J.G., Kuczynski, J., Stombaugh, J., Bittinger, K., Bushman, F.D., Costello, E.K., et al. (2010) QIIME Allows Analysis of High-Throughput Community Sequencing Data. Nature Methods 7: 33536.

Caporaso, J.G., Lauber, C.L., Walters, W.A., Berg-Lyons, D., Huntley J., Fierer, N., et al. (2012) Ultrahigh-throughput microbial community analysis on the Illumina HiSeq and MiSeq platforms. ISME J 6: $1621-24$.

Cordero, P.R.F., Bayly, K., Leung, P.M., Huang, C., Islam, Z.F., Schittenhelm, R.B., et al. (2019) Atmospheric carbon monoxide oxidation is a widespread mechanism supporting microbial survival. 
678

679

680

681

682

683

684

685

686

687

688

689

690

691

692

693

694

695

696

697

698

699

700

701

702

703

ISME J 13: 2868-2881.

Coskun, O.K., Ozen, V., Wankel, S.D., and Orsi, W.D. (2019) Quantifying population-specific growth in benthic bacterial communities under low oxygen using $\mathrm{H}_{2}{ }^{(18)} \mathrm{O}$. ISME J 5:1546-1559.

D'Hondt, S., Inagaki, F., Zarikian, C.A., Abrams, L.J., Dubois, N., Engelhardt, T., et al. (2015) Presence of oxygen and aerobic communities from sea floor to basement in deep-sea sediments. Nature Geosci 8: 299-304.

D'Hondt, S., Pockalny, R., Fulfer, V.M., and Spivack, A.J. (2019) Subseafloor life and its biogeochemical impacts. Nat Commun 10: 3519.

Durbin, A.M., and Teske, A. (2011) Microbial diversity and stratification of South Pacific abyssal marine sediments. Environ Microbiol 13: 3219-3234.

Duhamel, M., and Edwards, E.A. (2006) Microbial composition of chlorinated ethene-degrading cultures dominated by Dehalococcoides. FEMS Microbiol Ecol 58: 538-549.

Edgar, R.C. (2004) MUSCLE: multiple sequence alignment with high accuracy and high throughput. Nucleic Acids Res 32:1792-1797.

Edgar, R.C. (2010) Search and clustering orders of magnitude faster than BLAST. Bioinformatics 26: $2460-61$.

Edgar, R.C. (2013) UPARSE: highly accurate OTU sequences from microbial amplicon reads. Nat Methods 10: 996-998.

Estes, E.R., Pockalny, R., D'Hondt, S., Inagaki, F., Morono, Y., Murray, R.W., et al. (2019) Persistent organic matter in oxic subseafloor sediment. Nat Geosci 12: 126-131.

Fincker, M., Huber, J.A., Orphan, V.J., Rappé, M.S., Teske, A., and Spormann, A.M. (2020) Metabolic strategies of marine subseafloor Chloroflexi inferred from genome reconstructions. Environ Microbiol: in press, doi: 10.1111/1492-2920.15061.

Fullerton, H., Moyer, C.L. (2016) Comparative single-cell genomics of Chloroflexi from the Okinawa Trough deep-subsurface biosphere. Appl Environ Microb 82: 3000-3008.

Galperin, M.Y., Makarova, K.S., Wolf, Y.I., and Koonin, E.V. (2015) Expanded microbial genome 
bioRxiv preprint doi: https://doi.org/10.1101/2020.05.26.116590; this version posted May 27, 2020. The copyright holder for this preprint (which was not certified by peer review) is the author/funder, who has granted bioRxiv a license to display the preprint in perpetuity. It is made available under aCC-BY-NC-ND 4.0 International license.

704

705

706

707

708

709

710

711

712

713

714

715

716

717

718

719

720

721

722

723

724

coverage and improved protein family annotation in the COG database. Nucleic Acids Res 43: 261269.

Ghyselinck, J., Coorevits, A., Van Landschoot, A., Samyn, E., Heylen, K., and De Vos, P. (2013) An rpoD gene sequence based evaluation of cultured Pseudomonas diversity on different growth media. Microbiology 159: 2097-2108.

Gouy, M., Guindon, S., and Gascuel, O. (2010) SeaView version 4: a multiplatform graphical user interface for sequence alignment and phylogenetic tree building. Mol Biol Evol 27: 221-224.

Gupta, R.S., Chander, P., and George, S. (2013) Phylogenetic framework and molecular signatures for the class Chloroflexi and its different clades; proposal for division of the class Chloroflexi class. nov. into the suborder Chloroflexineae subord. nov., consisting of the emended family Oscillochloridaceae and the family Chloroflexaceae fam. nov., and the suborder Roseiflexineae subord. nov., containing the family Roseiflexaceae fam. nov. Anton van Leeuw 103: 99-119.

Hoehler, T.M., and Jørgensen, B.B. (2013) Microbial life under extreme energy limitation. Nat Rev Microbiol 11: 83-94.

Huber, W., Carey, V.J., Gentleman, R., Anders, S., Carlson, M., Carvalho, B.S., et al. (2015) Orchestrating high-throughput genomic analysis with Bioconductor. Nat Methods 12: 115-121.

Hug, L.A., Castelle, C.J., Wrighton, K.C., Thomas, B.C., Sharon, I., Frischkom, K.R., et al. (2013) Community genomic analyses constrain the distribution of metabolic traits across the Chloroflexi phylum and indicate roles in sediment carbon cycling. Microbiome 1: 1-17.

Imachi, H., Sakai, S., Lipp, J.S., Miyazaki, M., Saito, Y., Yamanaka, Y., et al. (2014) Pelolinea submarina gen. nov., sp. nov., an anaerobic, filamentous bacterium of the phylum Chloroflexi isolated from subseafloor sediment. Int J Syst Evol Micr 64: 812-818.

Inagaki, F., Nunoura, T., Nakagawa, S., Teske, A., Lever, M., Lauer, A., et al. (2006) Biogeographical distribution and diversity of microbes in methane hydrate-bearing deep marine sediments on the Pacific Ocean Margin. Proc Natl Acad Sci USA 103: 2815-2820.

Islam, Z.F., Cordero, P.R.F., Feng, J., Chen, Y.-J., Bay, S.K., Jirapanjawat, T., et al. (2019) Two 
Chloroflexi classes independently evolved the ability to persist on atmospheric hydrogen and carbon

731

732

733

734

735

736

737

738

739

740

741

742

743

744

745

746

747

748

749

750

751

752

753

754

755 monoxide. ISME J 13: 1801-1813.

Jørgensen, B.B., and Marshall, I. (2016) Slow microbial life in the seabed. Annu Rev Mar Sci 8: 311 332.

Jørgensen, B.B., Findlay, A.J., and Pellerin, A. (2019) The biogeochemical sulfur cycle of marine sediments. Front Microbiol 10: e849.

Kadnikov, V.V., Savvichev, A.S., Mardanov, A.V., Beletsky, A.V., Merkel, A.Y., Ravin, N.V., et al. (2019) Microbial communities involved in the methane cycle in the near-bottom water layer and sediments of the meromictic subarctic Lake Svetloe. Anton van Leeuw J Microb 112: 1801-1814.

Kallmeyer, J., Pockalny, R., Adhikari, R., Smith, D.C., D'Hondt, S. (2012) Global distribution of microbial abundance and biomass in subseafloor sediment. Proc Natl Acad Sci USA 109: 1621316216

Kaster, A., Blackwell-Mayer, K., Pasarell, B., and Spormann, A.M. (2014) Single cell study of Dehalococcoidetes species from deep-sea sediments of the Peruvian Margin. ISME J 8: 1831-1842.

Kawai, M., Futagami, T., Toyoda, A., Takaki, Y., Nishi, S., Hori, S., et al. (2014) High frequency of phylogenetically diverse reductive dehalogenase-homologous genes in deep subseafloor sedimentary metagenomes. Front Microbiol 5: e80.

Kirkpatrick, J.B., Walsh, E.A., and D’Hondt, S. (2019) Microbial selection and survival in subseafloor sediment. Front Microbiol 10: e956.

Kittelmann, S., and Friedrich, M.W. (2008) Novel uncultured Chloroflexi dechlorinate perchloroethene to trans-dichloroethene in tidal flat sediments. Environ Microbiol 10: 1557-1570.

Klatt, C.G., Liu, Z., Ludwig, M., Kühl, M., Jensen, S.I., Bryant, D.A., et al. (2013) Temporal metatranscriptomic patterning in phototrophic Chloroflexi inhabiting a microbial mat in a geothermal spring. ISME J 7: 1775-1789.

Krumins, V., Sun, W., Guo, J., Capozzi, S., Fennell, D.E., and Rodenburg, L.A. (2018) Sewer sediment bacterial communities suggest potential to transform persistent organic pollutants. Water Environ Res 
90: 2022-2029.

757

Landry, Z., Swan, B.K., Herndl, G.J., Stepanaukas, R., and Giovannoni, S.J. (2017) SAR202 genomes from the dark ocean predict pathways for the oxidation of recalcitrant dissolved organic matter. mBio 8: e00413-17.

Lloyd, K.G., Bird, J.T., Buongiorno, J., Deas, E., Kevorkian, R., Noordhoek, T., et al. (2020) Evidence for a growth zone for deep subsurface microbial clades in near-surface anoxic sediments. bioRxiv preprint doi: https://doi.org/10.1101/2020.03.24.005512.

Löffler, F.E., Yan, J., Ritalahti, K.M., Adrian, L., Edwards, E.A., Konstantinidis, K.T., et al. (2013) Dehalococcoides mccartyi gen. nov., sp. nov., obligately organohalide respiring anaerobic bacteria relevant to halogen cycling and bioremediation, belong to a novel bacterial class, Dehalococcoidia classis nov., order Dehalococcoidales ord. nov. and family Dehalococcoidaceae fam. nov., within the phylum Chloroflexi. Int J Syst Evol Microbiol 63: 625-635.

Loy, A., Duller, S., Baranyi, C., Mußmann, M., Ott, J., Sharon, I., et al. (2009) Reverse dissimilatory sulfite reductase as phylogenetic marker for a subgroup of sulfur-oxidizing prokaryotes. Environ Microbiol 11: 289-299.

Ludwig, W., Strunk, O., Westram, R., Richter, L., Meier, H., Yadhukumar, et al. (2004) ARB: a software environment for sequence data. Nucleic Acids Res 32: 1363-1371.

Matturro, B., Frascadore, E., and Rossetti, S. (2017) High-throughput sequencing revealed novel Dehalococcoidia in dechlorinating microbial enrichments from PCB-contaminated marine sediments. FEMS Microbiol Ecol 93: fix134.

Mehrshad, M., Rodriguez-Valera, F., Amoozegar, M.A., López-Garcia, P., and Ghai, R. (2018) The enigmatic SAR202 cluster up close: Shedding light on a globally distributed dark ocean lineage involved in sulfur cycling. ISME J 12: 655-668.

Müller, A.L., Kjeldsen, K.U., Rattei, T., Pester, M., and Loy A. (2015) Phylogenetic and environmental diversity of DsrAB-type dissimilatory (bi)sulfite reductases. ISME J 9: 1152-1165. 
781 Nunoura, T., Nishizawa, M., Hirai, M., Shimamura, S., Harnvoravongchai, P., Koide, O., et al. (2018)

782 Microbial diversity in sediments from the bottom of the Challenger Deep, the Mariana Trench. $783 \quad$ Microbes Environ 33: 186-194.

784

Orsi, W. D., Jørgensen, B.B., and Biddle J.F. (2016) Transcriptional analysis of sulfate reducing and chemolithoautotrophic sulfur oxidizing bacteria in the deep subseafloor. Environ Mcrobiol Rep 8: $452-460$.

Orsi, W. D., Richards, T. A., and Francis, W. R. (2018b) Predicted microbial secretomes and their target substrates in marine sediment. Nat Microbiol 3: 32-37.

Orsi, W.D. (2018) Ecology and evolution of seafloor and subseafloor microbial communities. Nat Rev Microbiol 16: 671-683.

Orsi, W.D., Vuillemin, A., Rodriguez, P., Coskun, Ö.K., Gomez-Saez, G.V., Morholz, V., and Ferdelman, T.G. (2020a). Metabolic activity analyses demonstrate that Lokiarchaeon exhibits homoacteogenesis in sulfidic marine sediments. Nat Microbiol 5: 248-255.

Orsi, W.D., Schink, B., Buckel, W., and Martin, W.F. (2020b) Physiological limits to life in anoxic subseafloor sediment. FEMS Microbiol Rev 44; fuaa004.

Ortega-Arbulù, A.-S., Pichler, M., Vuillemin, A., and Orsi, W.D. (2019) Effect of organic matter and low oxygen on the mycobenthos in a coastal lagoon. Environ. Microbiol. 21: 374-388.

Parkes, R., Webster, G., Cragg, B., Weightman, A.J., Newberry, C.J., Ferdelman, T.G., et al. (2005) Deep sub-seafloor prokaryotes stimulated at interfaces over geological time. Nature 436: 390-394.

Peters, J.W., Miller, A.-F., Jones, A.K., King, P.A., and Adams, A.W.W. (2016) Electron bifurcation. Curr Opin Chem Biol 31: 146-152.

Petro, C., Zäncker, B., Starnawski, P., Jochum, L.M., Ferdelman, T.G., Jørgebsen B.B., et al. (2019) Marine deep biosphere microbial communities assemble in near-surface sediments in Aarhus Bay. Front Microbiol 10: e758.

Pichler, M., Coskun, Ö.K., Ortega, A.S., Conci, N., Wörheide, G., Vargas, S., and Orsi, W.D. (2018) A 16S rRNA gene sequencing and analysis protocol for the Illumina MiniSeq platform. 
MicrobiologyOpen 7: e00611.

808

Pruesse, E., Quast, C., Knittel, K., Fuchs, B.M., Ludwig, W., Peplies, J., et al. (2007) SILVA: a comprehensive online resource for quality checked and aligned ribosomal RNA sequence data compatible with ARB. Nucleic Acids Res 35: 7188-7196.

Quast, C., Pruesse, E., Yilmaz, P., Gerken, J., Schweer, T., Yarza, P., et al. (2013) The SILVA ribosomal RNA gene database project: improved data processing and web-based tools. Nucleic Acids Res 41: 590-596.

Røy, H., Kallmeyer, J., Adhikari, R.R., Pockalny, R., Jørgensen, B.B., and D’Hondt, S. (2012) Aerobic microbial respiration in 86-million-year-old deep-sea red clay. Science 336: 922-925.

Salter, S.J., Cox, M.J., Turek, E.M., Calus, S.T., Cookson, W.O., Moffatt, M.F., et al. (2014) Reagent and laboratory contamination can critically impact sequence-based microbiome analyses. BMC Biology 12: e87.

Schuchmann, K., and Müller, V. (2019) Energetics and application of heterotrophy in acetogenic bacteria. Appl Environ Microb 82: 4056-4069.

Sewell, H.L., Kaster, A.-K., and Spormann, A.M. (2017) Homoacetogenesis in deep-sea Chloroflexi, as inferred by single-cell genomics, provides a link to reductive dehalogenation in terrestrial Dehalococcoidetes. mBio 8: e2022-17.

Shafaat, H.S., Rüdiger, O., Ogata, H., and Lubitz, W. (2013) [NiFe] hydrogenases: A common active site for hydrogen metabolism under diverse conditions. Geochim Cosmochim Ac 1827: 986-1002.

Shu, D., He, Y., Yue, H., and Wang, Q. (2015) Microbial structures and community functions of anaerobic sludge in six full-scale wastewater treatment plants as revealed by 454 high-throughput pyrosequencing. Bioresour Technol 186:163-172.

Solden, L., Lloyd, K., and Wrighton K. (2016) The bright side of microbial dark matter: lessons learnt from the uncultivated majority. Curr Opin Microbiol 31: 217-226.

Stamatakis, A. (2014) RAxML version 8: a tool for phylogenetic analysis and post-analysis of large phylogenies. Bioinformatics 30:1312-1313. 
833 Stamatakis, A., Aberer, A.J., Goll, C., Smith, S.A., Berger, S.A., Izquierdo-Carrasco, F. (2012)

834 RAxML-Light: a tool for computing terabyte phylogenies. Bioinformatics 28: 2064-2066.

835 Starnawski, P., Bataillon, T., Ettema, T.J.G., Jochum, L.M., Schreiber, L., Chen, X., et al. (2017)

836 Microbial community assembly and evolution in subseafloor sediment. Proc Natl Acad Sci USA 114:

$8372940-2945$.

838 Sun, L., Toyonaga, M., Ohashi, A., Matsuura, N., Tourlousse, D.M., Meng, X.-Y., et al. (2016) Isolation

839 and characterization of Flexilinea flocculi gen. nov., sp. nov., a filamentous, anaerobic bacterium

840 belonging to the class Anaerolineae in the phylum Chloroflexi. Int J Sys Evol Microb 66: 988-996.

841 Sutcliffe, I.C. (2011) Cell envelope architecture in the Chloroflexi: a shifting frontline in a phylogenetic

842 turf war. Environ Microbiol 13: 279-282.

843 Větrovský, T., and Badrian, P. (2013) The variability of 16S rRNA gene in bacterial genomes and its 844 consequences for bacterial community analyses. PLoS ONE 8: e57923.

845 Vignais, P.M., Billoud, B., and Meyer, J. (2001) Classification and phylogeny of hydrogenases. FEMS $846 \quad$ Microbiol Rev 25: 455-501.

847 Vuillemin, A., Ariztegui, D., Horn, F., Kallmeyer, J., Orsi, W.D., and the PASADO Science Team 848 (2018a) Microbial community composition along a 50,000-year lacustrine sediment sequence. FEMS $849 \quad$ Microbiol Ecol 94: fiy029.

850 Vuillemin, A., Horn, F., Friese, A., Winkel, M., Alawi, M., Wagner, D., et al. (2018b) Metabolic 851 potential of microbial communities from ferruginous sediments. Environ Microbiol 20: 4297-4313.

852 Vuillemin, A., Magritsch, T., Cöskun, Ö.M., Vargas, S., Wankel, S.D., Estes, E.R., et al. (2018c) 853 Metabolic potential and gene expression of the deep biosphere in oxic and anoxic abyssal clays from 854 the North Atlantic Ocean. SAME16 -16th Symposium on Aquatic Microbial Ecology 16: 212 855 (abstract PP-102).

856 Vuillemin, A., Wankel, S.D., Coskun, Ö.K., Magritsch, T., Vargas, S., Estes, E.R., et al. (2019) Archaea 857 dominate oxic subseafloor communities over multimillion-year time scales. Sci Adv 5: eaaw4108.

858 Walsh, E.A., Kirkpatrick, J.B., Rutherford, S.D., Smith, D.C., Sogin, M., and D'Hondt S. (2016) 
bioRxiv preprint doi: https://doi.org/10.1101/2020.05.26.116590; this version posted May 27, 2020. The copyright holder for this preprint (which was not certified by peer review) is the author/funder, who has granted bioRxiv a license to display the preprint in perpetuity. It is made available under aCC-BY-NC-ND 4.0 International license.

859

860

Bacterial diversity and community from seasurface to subseafloor. ISME J 10: 979-989.

Wasmund, K., Schreiber, L., Lloyd, K.G. Petersen, D.G., Schramm, A., Stepanauskas, R., et al. (2014)

Genome sequencing of a single cell of the widely distributed marine subsurface Dehalococcoidia, phylum Chloroflexi. ISME J 8: 383-397.

Wasmund, K., Mussmann, M., and Loy, A. (2017) The life sulfuric: microbial ecology of sulfur cycling in marine sediments. Environ Microbiol Rep 9: 323-344.

Wei, X., and Bauer, W.D. (1998) Starvation-induced changes in motility, chemotaxis, and flagellation of Rhizobium meliloti. Appl Environ Microbiol 64:1708-1714.

Wiechmann, A., Ciurus, S., Oswald, F., Seiler, V.N., and Müller V. (2020) It does not always take two to tango: "Syntrophy" via hydrogen cycling in one bacterial cell. ISME J 14: 1561-1570.

Wilms, R., Köpke, B., Sass, H., Chang, T.S., Cypionka, H., and Engelen, B. (2006) Deep biosphererelated bacteria within the subsurface of tidal flat sediments. Environ Microbiol 8: 709-719.

Yamada, T., Sekiguchi, Y., Hanada, S., Imachi, H., Ohashi, A., Harada, H., et al. (2006) Anaerolinea thermolimosa sp. nov., Levilinea saccharolytica gen. nov., sp. nov. and Leptolinea tardivitalis gen. nov., sp. nov., novel filamentous anaerobes, and description of the new classes Anaerolineae classis nov. and Caldilineae classis nov. in the bacterial phylum Chloroflexi. Int J Sys Evol Microb 56: $1331-1340$.

Yamada, T., Imachi, H., Ohashi, A., Harada, H., Hanada, S., Kamagata, Y., et al. (2017) Bellilinea caldifistulae gen. nov., sp. nov. and Longilinea arvoryzae gen. nov., sp. nov., strictly anaerobic, filamentous bacteria of the phylum Chloroflexi isolated from methanogenic propionate-degrading consortia. Int J Sys Evol Microb 57: 2299-2306.

Zhu, S., and Gao, B. (2020) Bacterial flagella loss under starvation. Trends Microbiol: in press.

Zhuang, W.-Q., Yi, S., Bill, M., Brisson, V.L., Feng, X., Men, Y., et al. (2014) Incomplete WoodLjungdahl pathway facilitates one-carbon metabolism in organohalide-respiring Dehalococcoides mccartyi. Proc Natl Acad Sci USA 111: 6419-6424.

Zinger, L., Amaral-Zettler, L.A., Fuhrman, J.A., Horner-Devine, M.C., Huse, S.M., Welch, D.B.M., et 
bioRxiv preprint doi: https://doi.org/10.1101/2020.05.26.116590; this version posted May 27, 2020. The copyright holder for this preprint (which was not certified by peer review) is the author/funder, who has granted bioRxiv a license to display the preprint in perpetuity. It is made available under aCC-BY-NC-ND 4.0 International license.

885

886

887

888

\section{Figures}

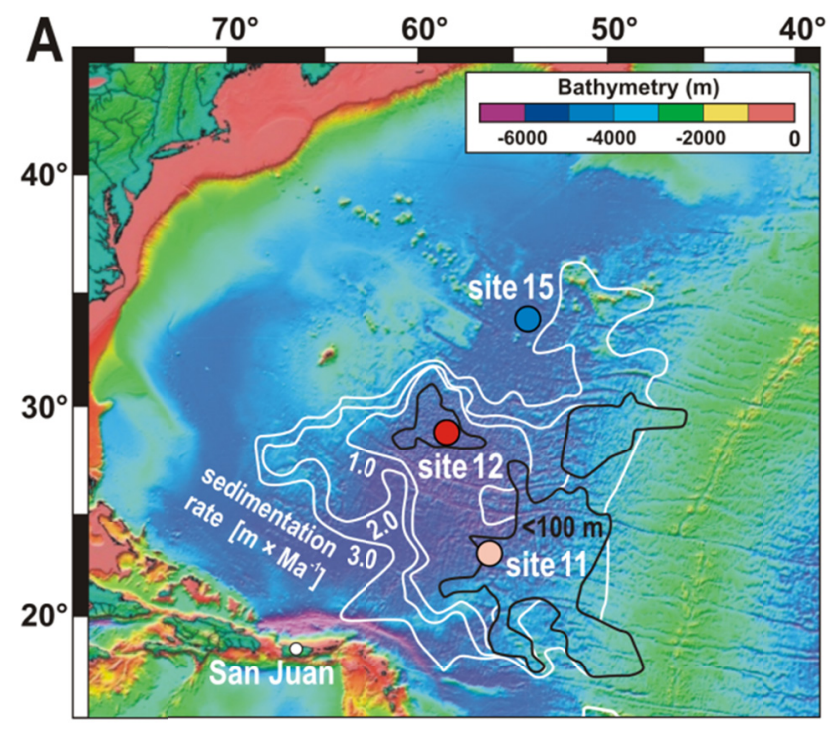

B Non-metric multidimensional scaling

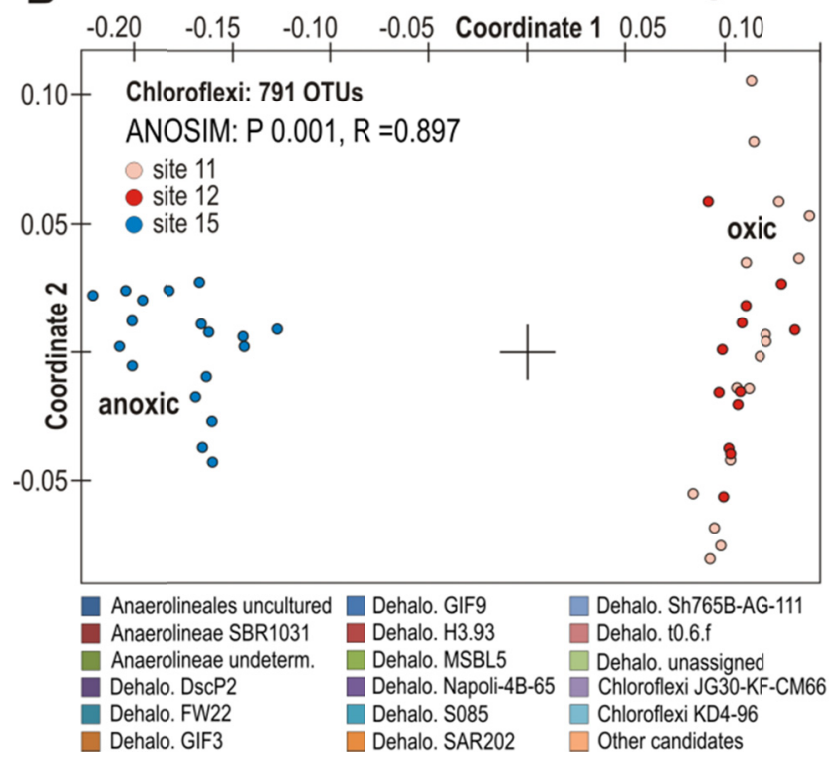

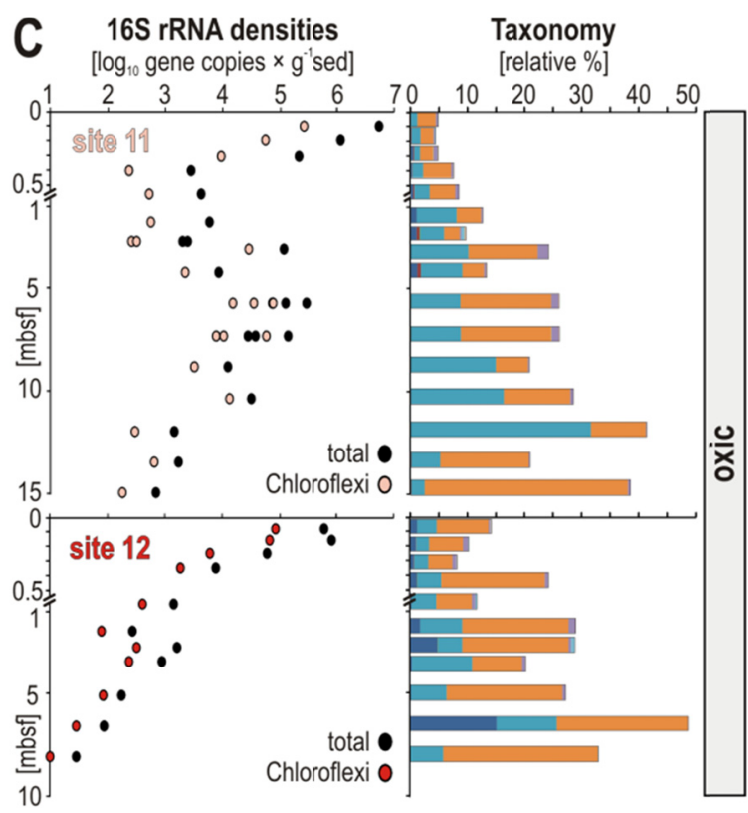
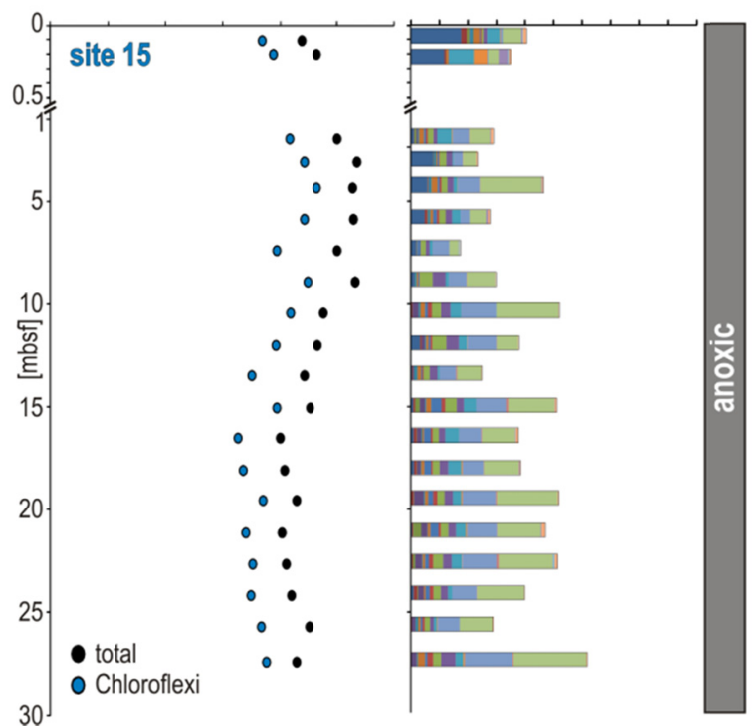

890 Figure 1. Map of sampling sites with bathymetry and sedimentation rate, and characterization of

891 Chloroflexi in terms of beta diversity, density and taxonomy at the three sites. (A) Map of

892 subseafloor sedimentation rate (after D'Hondt et al., 2015) with location of the three sampling sites. (B)

893 Non-metrical dimensional scaling (NMDS) plot based on all OTUs assigned to Chloroflexi across the

894 three sites. (C) Quantitative polymerase chain reaction (qPCR) of total (black dots) and qPCR-

895 normalized to Chloroflexi (colored dots) 16S rRNA genes [gene copies $\times \mathrm{g}^{-1}$ sed], and Chloroflexi

896 taxonomic assemblages [relative \%]. 
bioRxiv preprint doi: https://doi.org/10.1101/2020.05.26.116590; this version posted May 27, 2020. The copyright holder for this preprint (which was not certified by peer review) is the author/funder, who has granted bioRxiv a license to display the preprint in perpetuity. It is made available under aCC-BY-NC-ND 4.0 International license.

A. $R$ PpoD 8 SAR202 cluster, hycrothermal vent (CUV02662.1)

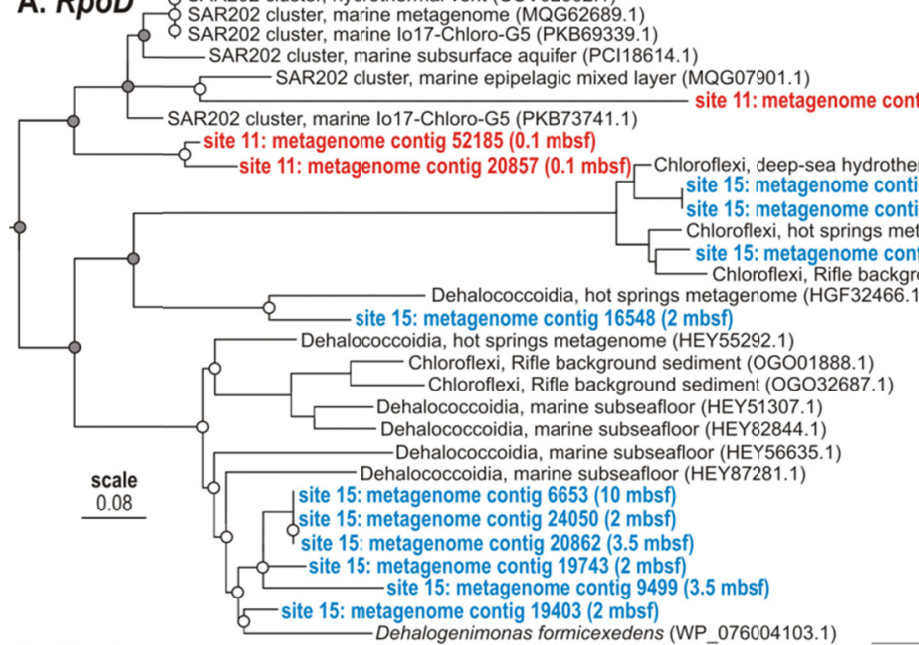

SAR202 cluster

B. DsrA

rDsra - $^{\text {Thiorhodovibrio sp. (figl631362.4) }}$ site 15 : transcript contig 22578 (2 mbsf)

- Thiotrichaceae SJ. (PCJ85917.1) - site 15: transcript contig $8498(5 \mathrm{mbsf})$

Desulfobacter sp.(MAF33453.1)

Desulfobulbaceae sp. (OEU78927.1)

Desulfotalea sp. (PHR24590.1)

- Site 15: transcript contig 8281 (2 mbsf)

Subsurface aquifer (OIP29714.1)

Groundwater metagenome (KAF01228

Smithella sp.(NLD82029.1)

scale $\begin{aligned} & \text { Dehalococcoidia clade, Aarhus Bay (AMQ24235.1) } \\ & \text { site 15: metagenome contig } 7526 \text { (5 mbsf) }\end{aligned}$

$0.2\{$ Uncultured SRB, Aarhus Bay (CAQ77304.1)

- site 15: metagenome contig 48141 (2 mbsf

C. DsrB

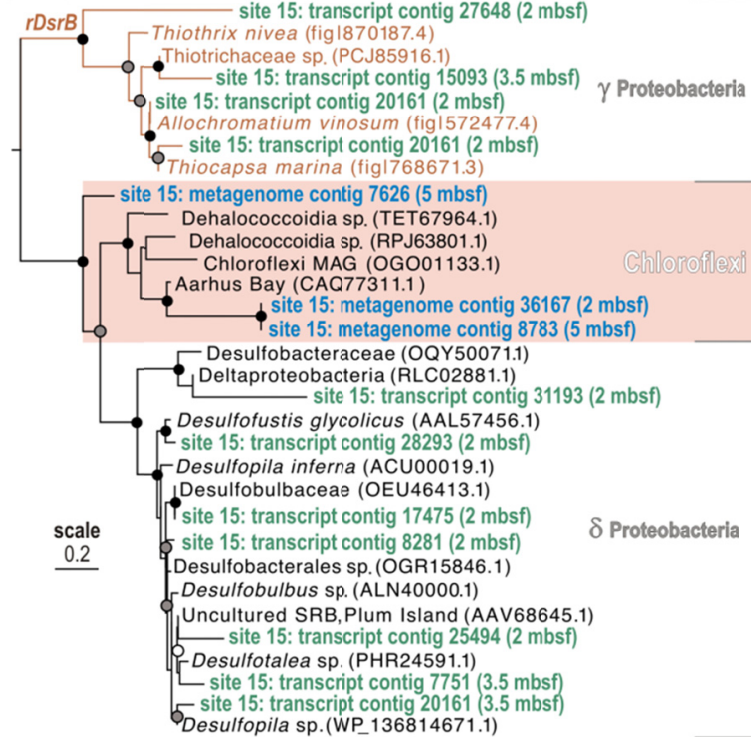

D. aprA

$\gamma$ Proteobacteria

$\delta$ Proteobacteria

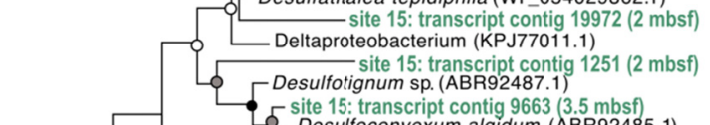

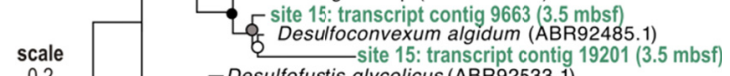

- Site 15: transcript contig 17799 (3.5 mbsf

- Desulfobacteraceae sp.(NNG02193.1)

site 15: transcript contig 5183 (3.5 mbsf)

site 15: transcript contig 12182 (2 mbsf)

Desulfosarcina alkanivorans (WP_155317927.1)

- site 15: transcript contig 13572 (3.5 mbs)

site 15: transcript contig 17289 (2 mbsf)

[ Desultosarcina widdelii (WP_155305421.

site 15: transcript contig 21502 (2 mbsf) $\delta$ Proteobacteria

Lesulfathalea tepidiphila (WP_054029362.1)

Deltaproteobacterium (KPJ77011.1)

0.2 Desulfofustis glycolicus (ABR92533.1)

site 15: transcript contig 11939 (3.5 mbsf)

D Desulfopila aestuarii (ACU0)

site 15: transcript contig 14010 (2 mbsf)

site 15: transcript contig 23272 (2 mbsf)

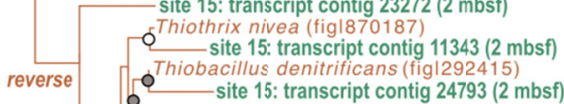

reverse $\alpha^{\text {Thiobacillus denitrificans (figl292415) }}$ site 15: transcript contig 24793 (2 mbsf) $\gamma$ Proteobacteria

site 15: transcript contig 20737 (2 mbsf)

-5 Endosymbiont of Riftia (figl1048808)

site 15: metagenome contig 11684 (5 mbsf)
site 15: metagenome contig 6703 (5 mbsf)
site 11: metagenome contig 64614 (0.1 mbsf)
Marine Group II Euryarchaeote (AIF 14688

site 15: metagenome contig 11684 (5 mbsf)
site 15: metagenome contig 6703 (5 mbsf)
site 11: metagenome contig 64614 (0.1 mbsf)
Marine Group II Euryarchaeote (AIF14688

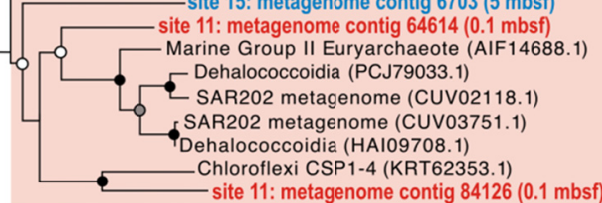

all taxa

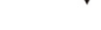

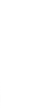

tagenome anoxic site 15

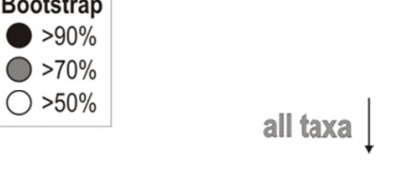





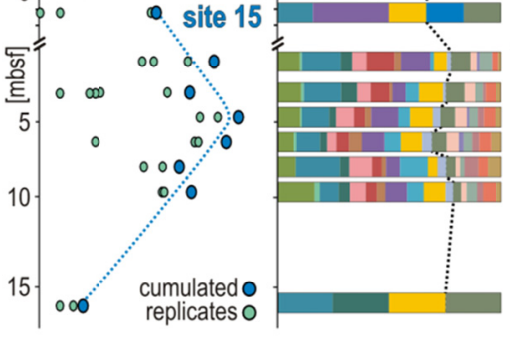

COG categories in transcriptomes only $\mathrm{N}$ : cell motility

O: protein turnover, chaperone

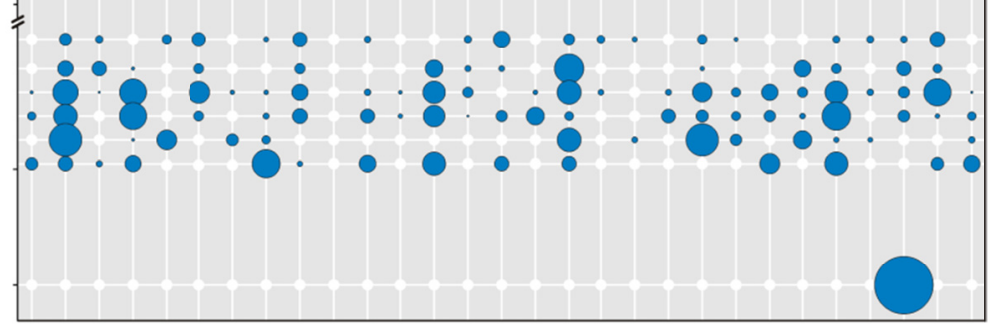

$\square$ P: inorganic ion transport Q: secondary metabolites $\square$ T: signal transduction

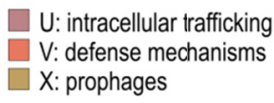

$\mathrm{X}$ : prophages

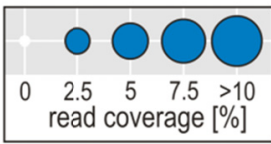

Figure 3. Open reading frames (ORFs) assigned to Chloroflexi, their COG categories and

metabolic potential obtained from metagenomes and metatranscriptomes. (A) Number of annotated

protein-encoding ORFs obtained from metagenomes and attributed to Chloroflexi with sediment depth;

relative abundances of different COG categories and metabolic functions obtained from metagenomes at

the three sites. (B) Number of annotated protein-encoding ORFs obtained from the metatranscriptomes and attributed to Chloroflexi with sediment depth; relative abundances of different COG categories and metabolic functions that are expressed at the anoxic site. 


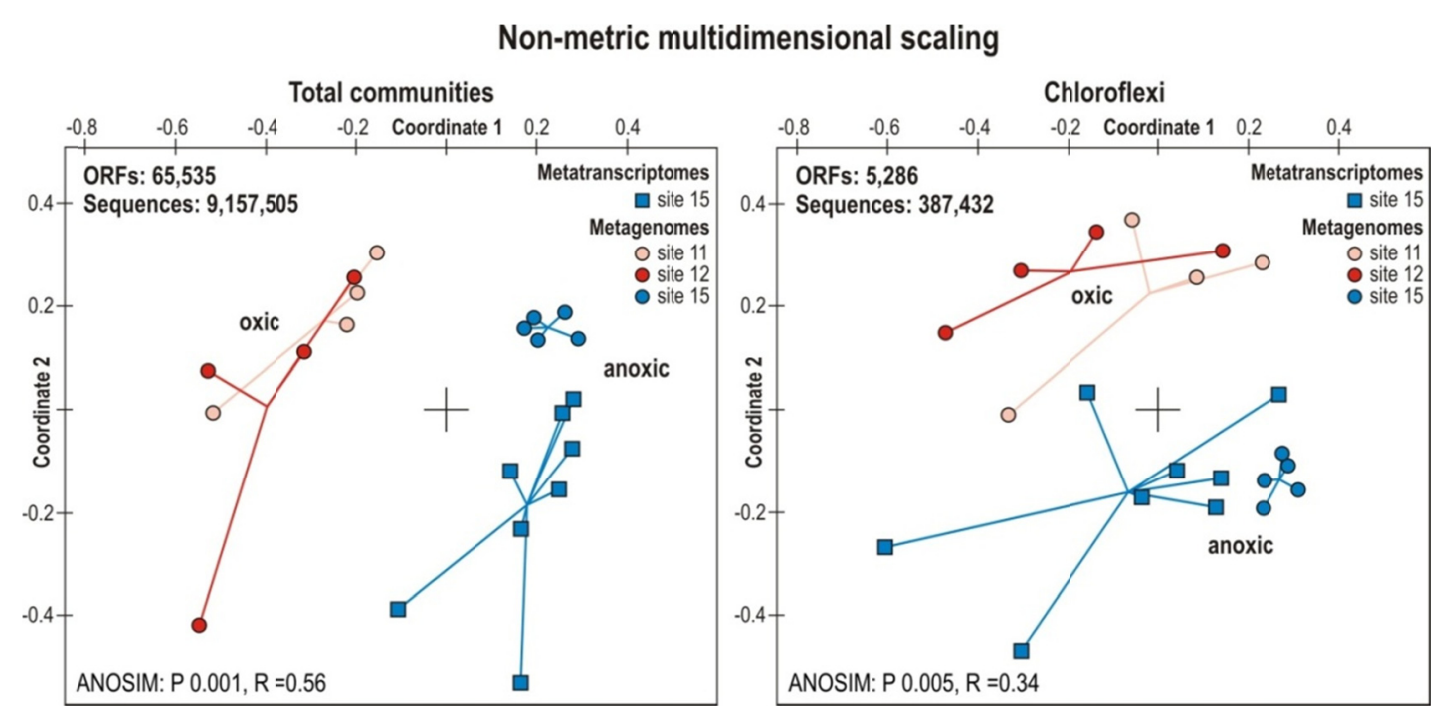

Figure 4. Non-metrical dimensional scaling (NMDS) plot for all three sites based on metagenomes and metatranscriptomes. (Left) NMDS plot for all three sites based on all ORFs from the

(circles) and metatranscriptomes (squares) assigned to Chloroflexi.

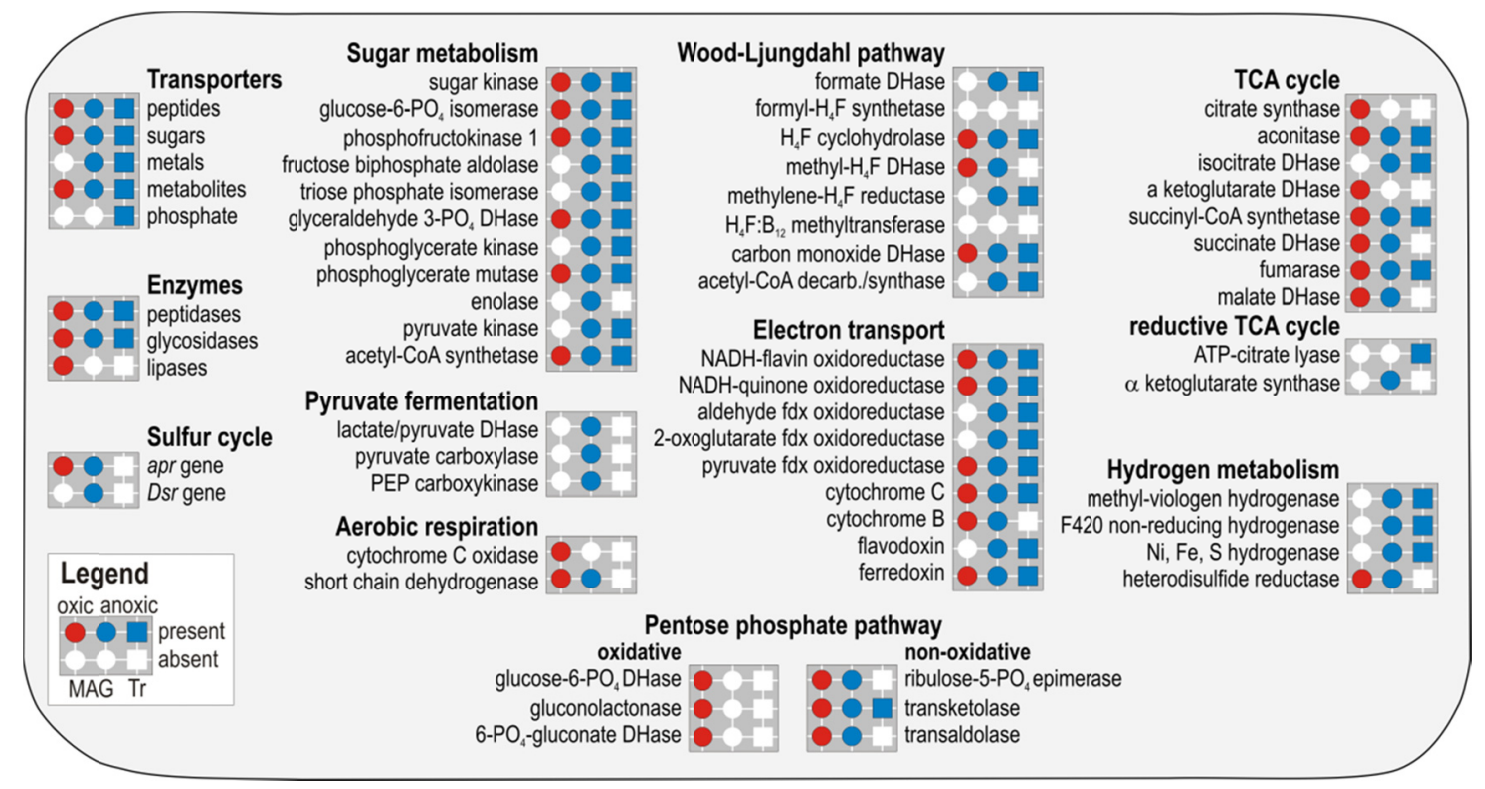

Figure 5. Presence and absence of Chloroflexi assigned predicted proteins in metagenomes and

metatranscriptomes. Presence (colored) or absence (white) of metabolic functions (circles) and expressed genes (squares) identified in the metagenomes and metatranscriptomes at the oxic (red) and anoxic (blue) sites across all depths sampled. Presence/absence of substrate transporters, catabolytic enzymes, apr and Dsr genes are shown on the left hand side. Metabolic pathways listed correspond to sugar metabolism, pyruvate fermentation, aerobic respiration, Wood-Ljungdahl pathway, electron transport, tricarboxylic acid cycle, hydrogen metabolism, and oxidative and non-oxidative pentose phosphate pathway. The complete list of genes with coverage is available as Tables S2-S3. 


\section{Supporting Information}

\section{Chloroflexi persisting for millions of years in oxic and anoxic deep-sea clay}

Aurèle Vuillemin, Zak Kerrigan, Steven D’Hondt, and William D. Orsi

The Supporting Information includes: 4 figures, 1 table, 2 separate excel sheets.
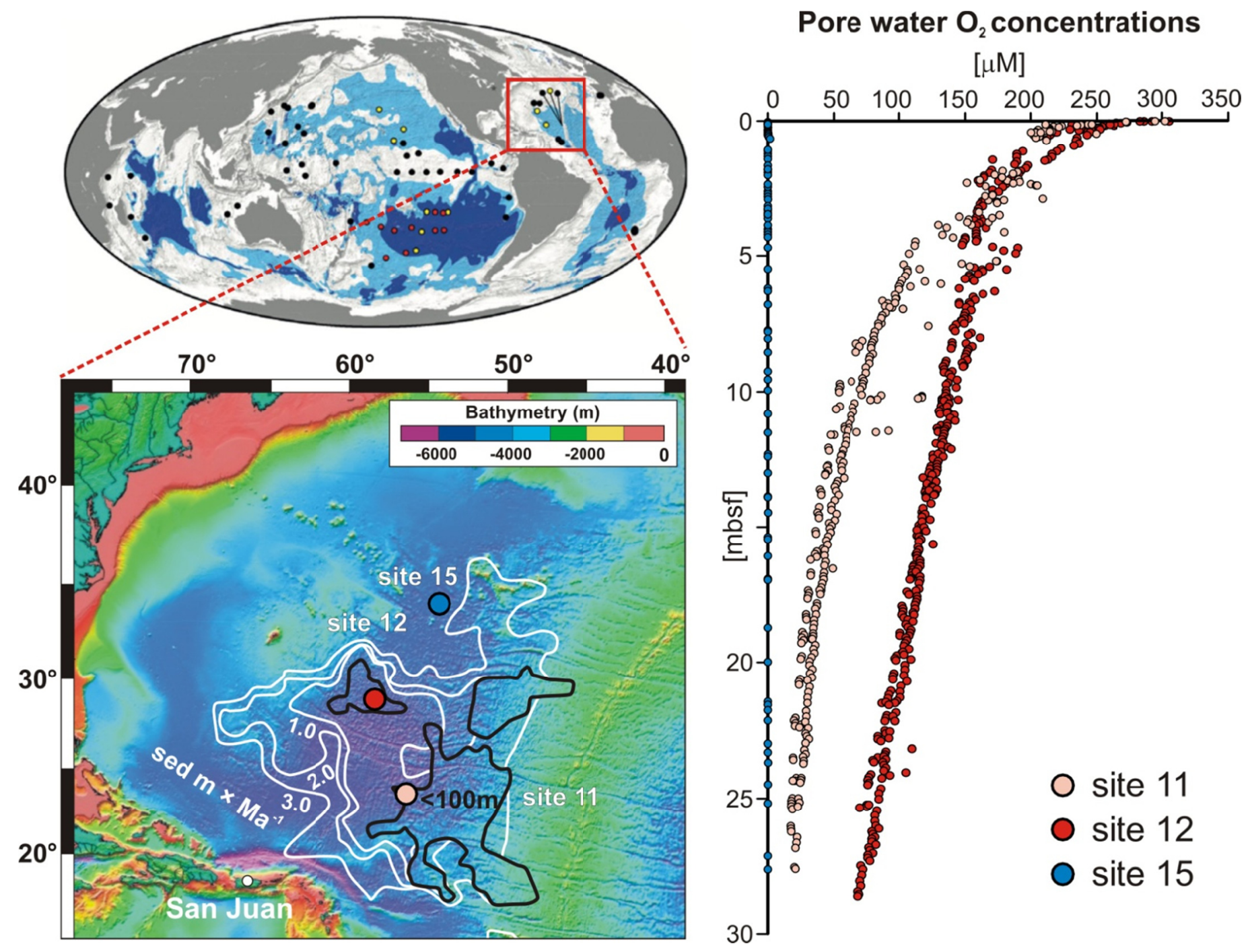

Supplementary Figure S1. Map of sampling site 11, 12 and 15 with bathymetry, sedimentation rates and pore water $\mathrm{O}_{2}$ profiles. (Left) Global map of subseafloor sedimentation rates and corresponding $\mathrm{O}_{2}$ penetration is modified from D'Hondt et al. (2015). (Right) Note that at site 11 and 12, there is $\mathrm{O}_{2}$ penetrating to 30 mbsf, whereas at site $15 \mathrm{O}_{2}$ is consumed immediately at the seafloor surface and the entire sediment sequence is anoxic. 
bioRxiv preprint doi: https://doi.org/10.1101/2020.05.26.116590; this version posted May 27, 2020. The copyright holder for this preprint (which was not certified by peer review) is the author/funder, who has granted bioRxiv a license to display the preprint in perpetuity. It is made available under ACC-BY-NC-ND 4.0 International license.
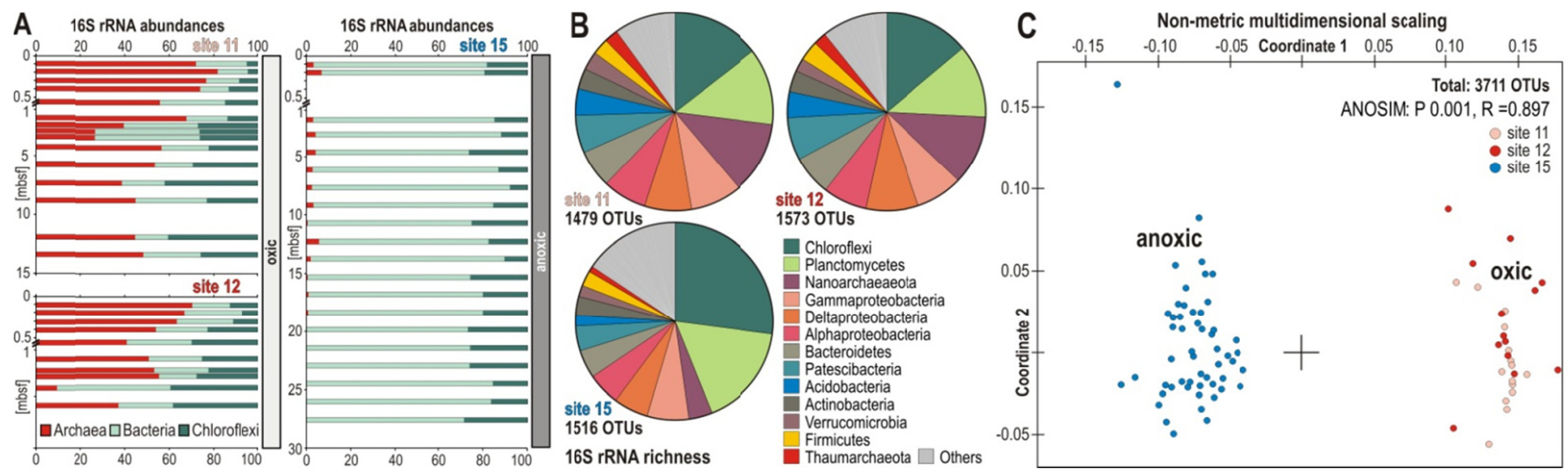

Supplementary Figure S2. Microbial abundance, richness beta diversity based on 16S rRNA genes. (A) Downcore profiles for the relative abundances of Archaea (red), Chloroflexi (dark green) and all other Bacteria (light green). (B) Richness of 16S rRNA genes based on the total number of OTUs. (C) Non-metrical dimensional scaling (NMDS) plot for all three sites based on all OTUs obtained from 16S rRNA gene amplicons, with significant separation between oxic and anoxic sediment.

\section{Oxic sites}

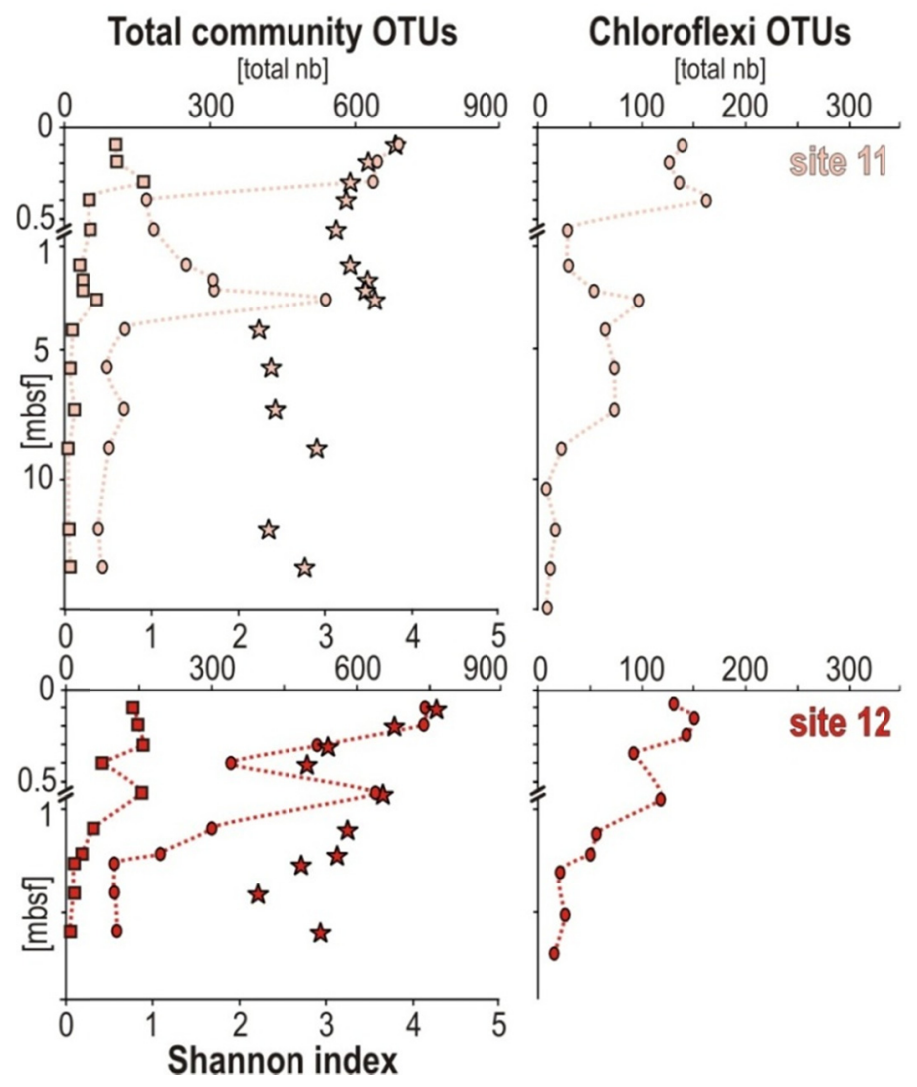

\section{Anoxic site}

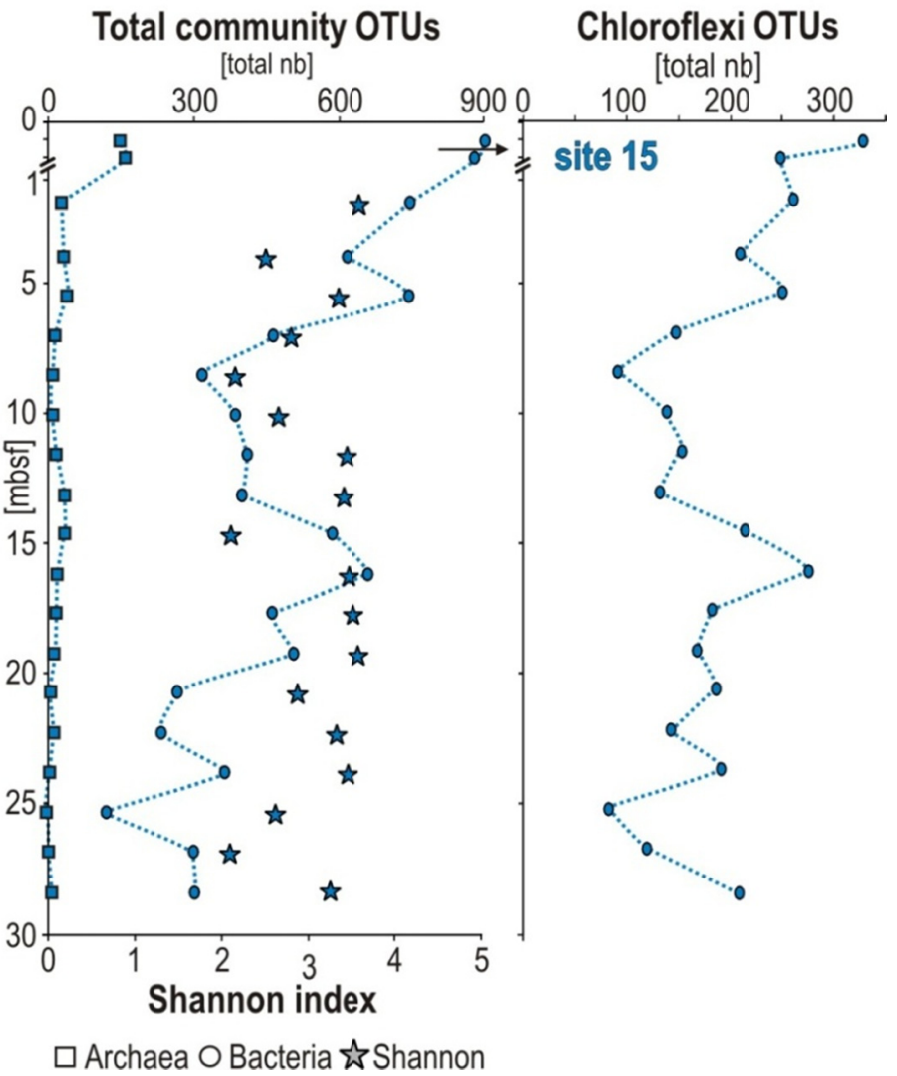

Supplementary Figure S3: Alpha diversity for whole communities and Chloroflexi at the three sites. (Left) Total number of OTUs assigned to Archaea (squares), and Bacteria (circles) with Shannon indices (stars) calculated for the whole populations at the two oxic sites; number of OTUs assigned to Chloroflexi at the two oxic sites. (Right) Same indices calculated for populations from the anoxic site. 
bioRxiv preprint doi: https://doi.org/10.1101/2020.05.26.116590; this version posted May 27, 2020. The copyright holder for this preprint (which was not certified by peer review) is the author/funder, who has granted bioRxiv a license to display the preprint in perpetuity. It is made available under ACC-BY-NC-ND 4.0 International license.

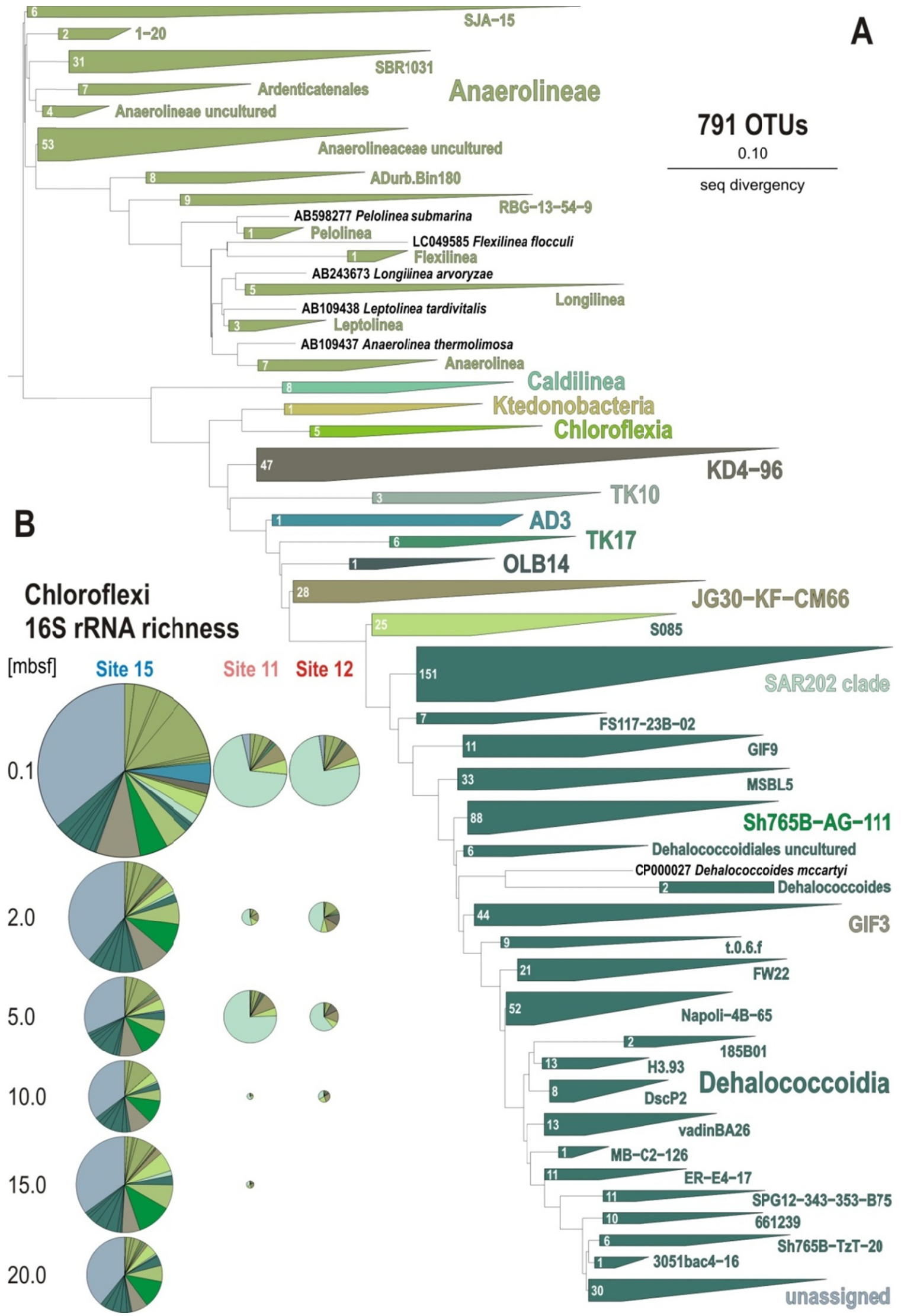

Supplementary Figure S4: Phylogenetic analysis of 16S rRNA genes (V4 hypervariable region). (A) Phylogenetic tree obtained for all operational taxonomic units (OTUs) assigned to Chloroflexi in this study. (B) Pie charts displaying 16S rRNA gene richness of the whole assemblages of Chloroflexi for each of the three sites and at each sediment depth. The radii of pie charts are proportional to the number of OTUs. 
bioRxiv preprint doi: https://doi.org/10.1101/2020.05.26.116590; this version posted May 27, 2020. The copyright holder for this preprint (which

was not certified by peer review) is the author/funder, who has granted bioRxiv a license to display the preprint in perpetuity. It is made available under aCC-BY-NC-ND 4.0 International license.

\begin{tabular}{|c|c|c|c|c|c|c|c|}
\hline Metagenomes & depth [m] & \# sequences & \# contigs & \# mapped reads & \# annotated ORFs & Accession no. & Run Accession no. \\
\hline \multirow{5}{*}{ Site 11} & 0.1 & $15,314,358$ & 104,349 & $10,153,456$ & 42,254 & SAMN10924458 & SRX5372537 \\
\hline & 0.9 & $6,479,556$ & 8.857 & $5,103,508$ & 5,137 & SAMN10924458 & SRX5372538 \\
\hline & 2.8 & $5,593,704$ & 8.952 & $5,126,686$ & 3,871 & SAMN10924458 & SRX5372539 \\
\hline & 7.4 & $10,074,790$ & 602 & $8,235,415$ & 276 & SAMN10924458 & SRX5372540 \\
\hline & 15 & $8,920,356$ & 144 & $7,503,283$ & 18 & SAMN10924458 & SRX5372541 \\
\hline \multirow{4}{*}{ Site 12} & 0.1 & $5,298,416$ & 17.05 & $4,181,095$ & 9,041 & SAMN10924459 & SRX5372542 \\
\hline & 0.9 & $3,961,194$ & 3.464 & 3.741 .957 & 2,151 & SAMN10924459 & SRX5372543 \\
\hline & 3.5 & $6,528,088$ & 1.407 & $6,200,598$ & 522 & SAMN10924459 & SRX5372544 \\
\hline & 5.1 & $5,353,236$ & 32.673 & $7,503,283$ & 67 & SAMN10924459 & SRX5372545 \\
\hline \multirow{5}{*}{ Site 15} & 2.1 & $9,294,114$ & 29.185 & $8,723,374$ & 13,134 & SAMN13317858 & SRR10481892 \\
\hline & 3.5 & $9,226,836$ & 15.319 & $8,517,416$ & 22,876 & SAMN13317859 & SRR10481891 \\
\hline & 5.2 & $4,158,110$ & 12.734 & $3,488,721$ & 9,137 & SAMN13317860 & SRR10481887 \\
\hline & 15 & $8,321,518$ & 10.194 & $7,435,919$ & 8,568 & SAMN13317861 & SRR10481886 \\
\hline & 29 & $10,746,984$ & 2.725 & $10,039,210$ & 2,894 & SAMN13317862 & SRR10481885 \\
\hline Transcriptomes & depth [m] & \# sequences & \# contigs & \# mapped reads & \# annotated ORFs & Accession no. & Run Accession no. \\
\hline \multirow{24}{*}{ Site 15} & $0.1(\mathrm{~A})$ & $4,025,956$ & $1 ' 795$ & $3^{\prime} 104^{\prime} 523$ & 3,343 & SAMN13317863 & SRR10481884 \\
\hline & $0.1(\mathrm{~B})$ & $3,532,876$ & $2^{\prime} 044$ & $2 ' 770^{\prime} 901$ & 98 & SAMN13317863 & SRR10481884 \\
\hline & $0.1(\mathrm{C})$ & $4,960,078$ & $3^{\prime \prime 174}$ & $4^{\prime} 055^{\prime} 833$ & 305 & SAMN13317863 & SRR10481884 \\
\hline & $2.1(\mathrm{~A})$ & $5,193,626$ & $2^{\prime} 382$ & $3^{\prime} 243^{\prime} 072$ & 329 & SAMN13317864 & SRR10481883 \\
\hline & $2.1(\mathrm{~B})$ & $6,188,052$ & $1^{\prime \prime} 782$ & $5^{\prime} 327^{\prime} 917$ & 188 & SAMN13317864 & SRR10481883 \\
\hline & $2.1(\mathrm{C})$ & $21,222,363$ & $31^{\prime \prime 254}$ & $19^{\prime} 007^{\prime} 366$ & 276 & SAMN13317864 & SRR10481883 \\
\hline & $3.5(\mathrm{~A})$ & $3,640,918$ & 861 & $3^{\prime} 121^{\prime} 393$ & 152 & SAMN13317865 & SRR10481882 \\
\hline & $3.5(\mathrm{~B})$ & $2,017,858$ & 546 & 1'612'249 & 135 & SAMN13317865 & SRR10481882 \\
\hline & $3.5(\mathrm{C})$ & 3'419'882 & $1^{\prime \prime 124}$ & $2^{\prime} 343^{\prime} 420$ & 2,963 & SAMN13317865 & SRR10481882 \\
\hline & $3.5(\mathrm{D})$ & $3^{\prime \prime} 054^{\prime} 074$ & 746 & $2^{\prime} 420^{\prime} 948$ & 1,827 & SAMN13317865 & SRR10481882 \\
\hline & $3.5(E)$ & 1'949'964 $^{\prime}$ & 550 & $1^{\prime} 428^{\prime} 941$ & 1,304 & SAMN13317865 & SRR10481882 \\
\hline & $3.5(\mathrm{~F})$ & 2'742'258 & 656 & 2 2'298'551 & 1,545 & SAMN13317865 & SRR10481882 \\
\hline & $3.5(\mathrm{G})$ & $3^{\prime} 093^{\prime} 748$ & 1030 & $2^{\prime} 410^{\prime} 463$ & 258 & SAMN13317865 & SRR10481882 \\
\hline & $5.2(\mathrm{~A})$ & $5^{\prime} 347^{\prime} 824$ & $10^{\prime} 204$ & $2^{\prime} 001^{\prime} 032$ & 1,262 & SAMN13317866 & SRR10481881 \\
\hline & $5.2(\mathrm{~B})$ & $3^{\prime} 673^{\prime} 384$ & $6^{\prime} 075$ & 1'142'750 & 1,098 & SAMN13317866 & SRR10481881 \\
\hline & $6.7(A)$ & 4'672'286 $^{\prime}$ & $5^{\prime} 583$ & $1^{\prime} 712^{\prime} 037$ & 1,748 & SAMN13317867 & SRR10481880 \\
\hline & $6.7(\mathrm{~B})$ & $7^{\prime} 253^{\prime} 508$ & $6^{\prime} 654$ & $2^{\prime} 396^{\prime} 752$ & 1,493 & SAMN13317867 & SRR10481880 \\
\hline & $8.2(\mathrm{~A})$ & $5^{\prime} 311^{\prime} 371$ & $3^{\prime} 378$ & 3'834'338 & 2,730 & SAMN13317868 & SRR10481890 \\
\hline & $8.2(\mathrm{~B})$ & $6^{\prime} 140^{\prime} 536$ & $2^{\prime} 055$ & $2^{\prime} 666^{\prime} 190$ & 285 & SAMN13317868 & SRR10481890 \\
\hline & $8.2(C)$ & $3^{\prime} 405^{\prime} 518$ & $1^{\prime} 312$ & $22^{\prime} 424^{\prime} 526$ & 306 & SAMN13317868 & SRR10481890 \\
\hline & $9.7(\mathrm{~A})$ & $6^{\prime} 159^{\prime} 540$ & 3'346 & $3^{\prime} 256^{\prime} 870$ & 623 & SAMN13317869 & SRR10481889 \\
\hline & $9.7(\mathrm{~B})$ & $4^{\prime} 494^{\prime} 022$ & $2 ' 571$ & 1'519'639 & 560 & SAMN13317869 & SRR10481889 \\
\hline & $15.9(A)$ & 1'091'556 & $1^{\prime \prime 192}$ & $849^{\prime} 855$ & 72 & SAMN13317870 & SRR10481888 \\
\hline & $15.9(\mathrm{~B})$ & $3^{\prime} 214^{\prime} 672$ & 885 & $2 ' 790 ' 696$ & 132 & SAMN13317870 & SRR10481888 \\
\hline
\end{tabular}

Supplementary Table S1: Sequencing and assembly results for the subseafloor metagenomes at site 11, 12 and 15, and transcriptomes at site 15 with their corresponding accession and run accession numbers. 